\title{
Anomalous Solute Diffusivity in Ionic Liquids: Label-Free Visualization and Physical Origins
}

\author{
Alexandra V. Bayles, Connor S. Valentine, ${ }^{*}$ Till Überrück, ${ }^{\dagger}$ Scott P. O. Danielsen, Songi Han, \\ Matthew E. Helgeson, and Todd M. Squires \\ University of California, Santa Barbara, Department of Chemical Engineering, University of California, \\ Santa Barbara, California 93106, USA
}

(Received 10 August 2018; revised manuscript received 5 November 2018; published 18 March 2019)

Dynamic diffusion of molecular solutes in concentrated electrolytes plays a critical role in many applications but is notoriously challenging to measure and model. This challenge is particularly true in the extreme case of ionic liquids (ILs), fluids composed entirely of cations and anions. Solute diffusivities in ILs show a strong concentration dependence, broadening the already vast IL design space and rendering conventional, sample-by-sample measurements impractical for screening. To gain better mechanistic insight into transport in this class of fluids, here we demonstrate a method to visualize the spatiotemporal evolution of concentration fields using microfluidic Fabry-Perot interferometry, enabling diffusivity measurements over an entire composition range within a single experiment. We focus on the absorption and diffusion of water, as both a model solute and a ubiquitous contaminant, within alkylmethylimidazoliumhalide ILs. Notably, the Stokes-Einstein relation underpredicts water diffusivities ten- to 50-fold, indicating that water does not experience these ILs as continuum liquids. Based on these measurements, together with wide-angle x-ray scattering and pulsed-field gradient NMR measurements, we propose a new mechanistic framework in which water molecules hop between ion pairs within the IL, which acts as an immobile matrix over timescales relevant for water diffusion. In this case, diffusion is an activated process, with hops between hydrogen-bonding sites over an energetic barrier that decreases linearly with the water fraction. The functional form of the activation energy is consistent with NMR chemical shift measurements, which indicate that hydrogen bonding weakens in linear proportion to the water fraction. This simple model contains the key ingredients required to accurately predict the measured trends in diffusivity - an (Arrhenius) temperature dependence and an exponential composition dependence-for a range of cations, anions, water contents, and temperatures. Our results suggest a general mechanism for anomalously fast diffusion in ILs, where solutes "hop" between binding sites more quickly than the ions rearrange.

DOI: 10.1103/PhysRevX.9.011048

\section{INTRODUCTION}

Ionic liquids (ILs) — salts that are liquid below $100{ }^{\circ} \mathrm{C}-$ possess unique physicochemical properties including negligible volatility, moderate conductivities, variable hydrophilicity, and high thermal and electrochemical stability windows [1-5]. Because these properties can be tuned

\footnotetext{
*Also at Carnegie Mellon University Department of Chemical Engineering, Carnegie Mellon University, Pittsburgh, Pennsylvania 15213, USA.

${ }^{\dagger}$ Also at RWTH Aachen University, Institute of Technical and Macromolecular Chemistry, RWTH Aachen University, D-52074 Aachen, Germany.

tsquires@ucsb.edu

Published by the American Physical Society under the terms of the Creative Commons Attribution 4.0 International license. Further distribution of this work must maintain attribution to the author(s) and the published article's title, journal citation, and DOI.
}

Subject Areas: Chemical Physics, Fluid Dynamics, Soft Matter

through ion choice, ILs are commonly described as designer solvents that can be synthesized to suit a particular application [6]. Specifically, since ILs can be designed to dissolve both polar and nonpolar compounds, they are increasingly being considered as replacements for common molecular solvents in processes including gas purification [7-13], liquid-liquid extraction [14-19], carbon capture [20-24], metal processing [25-29], and homogeneous catalysis [5,30-32]. In these applications, ILs offer improved selectivity, efficient recyclability, and reduced emissions over traditional, often volatile organic solvents [33]. Large-scale implementation of ILs, however, has been hindered by the cost as well as the challenge in identifying appropriate ILs from the approximately $10^{6}$ binary ILs thought to exist [34]. This vast synthesis space contributes to the IL cost: while it appears feasible to produce individual ILs economically at scale [35], one must first identify the appropriate IL to design the reaction process.

The widespread realization of ILs as task-specific solvents requires mechanistic understanding of IL-solute 
interactions during diffusion and transport. For example, the feasibility of green separation and reaction strategies depends on how quickly extracts, reagents, and products diffuse through ILs. The simplest model for predicting solute diffusivity $(D)$ is the Stokes-Einstein (SE) relation

$$
D_{\mathrm{SE}}=\frac{k_{B} T}{C \pi \eta R},
$$

where $\eta$ is the bulk viscosity of the surrounding liquid, $R$ is the hydrodynamic radius of the solute, and $C$ is a constant between 6 (no-slip boundary) and 4 (perfect slip). The denominator in Eq. (1) follows directly from a solution to the continuum fluid mechanics equations and predicts translational diffusion of molecular solutes within continuum liquids quite accurately under appropriate conditions. Indeed, measured self-diffusion coefficients of cations and anions in neat ILs typically lie within a factor of 2 of $D_{\mathrm{SE}}$ based on the (macroscopically) measured viscosity of the IL [36].

Anomalously large diffusivities in ILs have been reported, however, for electrochemically neutral solutes (both polar and nonpolar) that are smaller than the average ion size [37,38]. Such violations of the Stokes-Einstein relation immediately reveal a breakdown of the continuum approximation. Instead, solutes might hop from site to site-like dopant diffusion in solids - or translate within one of the various self-assembled mesostructures found in many ILs. Extensive x-ray [39-45] and neutron scattering [46,47] studies, combined with molecular dynamics simulations [42-45,48-50], reveal neat ILs to exhibit a rich spectrum of nanostructures absent in conventional solvents [51,52]. The emergence of polar and apolar domains, and the affinity of particular solutes for them, is coupled to the mobility of those solutes. For example, Araque et al. compute solute trajectories in dynamically heterogeneous ILs and argue that neutral solutes are often localized within stiff, cagelike domains, occasionally hopping to a neighboring caging domain through the "soft" domains that separate them, where mobility is enhanced $[37,38]$. The resulting diffusivity exceeds Stokes-Einstein predictions [Eq. (1)], which depends upon an IL viscosity $\eta$ measured via the continuous flow and rearrangement of these stiff domains.

It is currently unclear how these anomalous dynamics manifest under more concentrated solute conditions. The mesostructure may change with the solute concentration due to IL-solute interactions, particularly at high solute concentrations $[53,54]$. The strong coupling between diffusion and the mesostructure near infinite dilution prompts many uncertainties in more concentrated solutions, necessitating studies of composition-dependent solute transport. Indeed, traditional pulsed-field gradient-NMR (PFGNMR) studies reveal differences between ion and solute mobilities [55-58]. However, PFGNMR probes self-diffusion in equilibrium mixtures-meaning that concentration dependence can be measured only sample by sample. Moreover, PFGNMR cannot capture concentration gradients found in many practical applications, and measurements are limited to NMR-active or isotopically labeled species.

To complement these techniques and open new possibilities to probe transient processes in ILs, we develop microfluidic Fabry-Perot interferometry ( $\mu$ FPI) [59,60], which allows solute concentration profiles to be directly visualized as they evolve in space and time. An immediate benefit of $\mu$ FPI is that a single experiment enables concentration-dependent diffusivities to be measured over much (or even all) of composition space. Here, we use $\mu$ FPI to visualize water as it is absorbed from a vapor phase into a series of 1-alkylmethylimidazolium-halide ILs $\left[\mathrm{C}_{n} \operatorname{mim}\right][\mathrm{X}]$, specifically, $\left[\mathrm{C}_{6} \mathrm{mim}\right][\mathrm{I}], \quad\left[\mathrm{C}_{6} \mathrm{mim}\right][\mathrm{Br}]$, $\left[\mathrm{C}_{6} \mathrm{mim}\right][\mathrm{Cl}]$, and $\left[\mathrm{C}_{4} \mathrm{mim}\right][\mathrm{I}]$. This class of ionic liquids is particularly hygroscopic $[61,62]$ and serves as a model, task-specific IL chosen to absorb a neutral polar solute. Additionally, $\mathrm{H}_{2} \mathrm{O}$ is ubiquitous in any process operating in ambient conditions, whether it acts as an undesired impurity [61] or an enhancing additive [63].

Our results suggest water diffuses via activated "hops" between relatively immobile cations (or clusters thereof), akin to diffusion along a lattice in solids. The activation energy increases with anion electronegativity and decreases with water content. Our model offers both conceptual guidance and quantitative predictions for water diffusivity. More broadly, it offers insight into the selection and design of task-specific ILs.

\section{TRANSIENT SORPTION-DIFFUSION MEASUREMENTS}

We recently developed $\mu$ FPI $[59,60]$ as a label-free technique to visualize and measure the spatiotemporal evolution of concentration fields, including those near liquid interfaces. Experimental and analytic details are provided in the Appendixes. Briefly, the surfaces of a microfluidic device [Fig. 1(a)] are coated with a semireflective aluminum film. Light passed through the device interferes to form fringes of equal chromatic order (FECO), at wavelengths $\lambda_{0}^{i}$ that are resolved with a spectrometer paired with a highresolution digital video camera. When the refractive index changes by $\Delta n(y, t)$ - e.g., as solute diffuses in the $y$ direction - the FECO wavelengths change via

$$
\Delta \lambda^{i}(y, t)=\frac{\Delta n(y, t)}{n_{0}} \lambda_{0}^{i} .
$$

Subpixel FECO tracking algorithms allow $\Delta n$ to be reliably measured in $\mu$ FPI with a resolution of $2 \times 10^{-5}$ refractive index unit (RIU), which can then be related to changes in solute concentration using a separate $n(c)$ refractometry measurement [59]. For example, refractive indices of $\mathrm{IL}-\mathrm{H}_{2} \mathrm{O}$ mixtures grow linearly with the water volume fraction (Appendix C, Fig. 7) [64]. Evolving refractive 

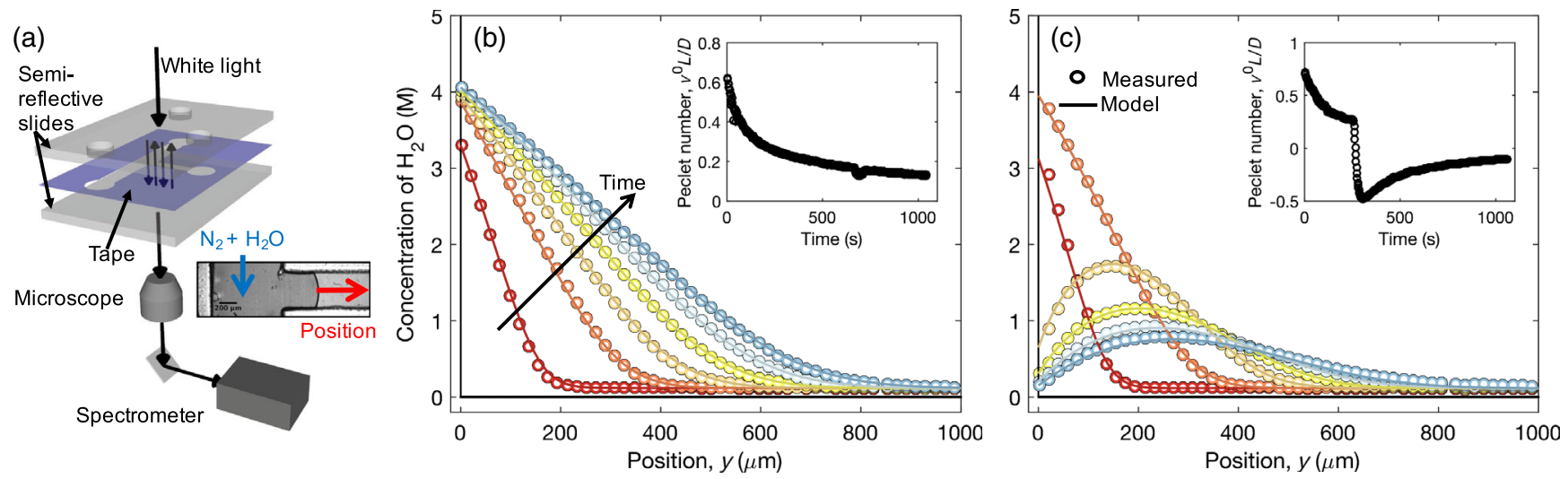

FIG. 1. Measuring concentration gradient-driven diffusion of $\mathrm{H}_{2} \mathrm{O}$ in ILs (example shown: [C $\mathrm{C}_{6}$ mim][I]). (a) Optical train of a microfluidic Fabry-Perot interferometry device. Solute $\left(\mathrm{H}_{2} \mathrm{O}\right)$ gradients are manipulated by switching the composition of a flowing vapor stream in contact with a stationary IL plug in a T-junction geometry. The experimentally measured $\mathrm{H}_{2} \mathrm{O}$ absorption (b) and desorption (c) fronts (circles) compare well with a numerical diffusion model [solid line, Eq. (3)]. Every tenth point in space is included; other points are excluded for clarity. Profiles are plotted at $3 \mathrm{~min}$ increments and change from red to blue with increasing time. Graphical insets show the dimensionless advective velocity fit from the concentration and the slope measured at the interface.

index profiles $n(y, t)$ can thus be converted to dynamic $\mathrm{H}_{2} \mathrm{O}$ concentration profiles $c_{\mathrm{H}_{2} \mathrm{O}}(y, t)$, as water sorbs into and out of an IL of interest [Figs. 1(b) and 1(c)]. In these experiments, the concentration is measured with a minimum spatial resolution of $1.92 \mu \mathrm{m}$ at $0.5 \mathrm{~Hz}$ over a period of 20-30 min.

In the water-IL studies described here, we controllably generate concentration gradients by filling the stem of a $\mathrm{T}$ junction with an IL and flowing gas in the channel perpendicular to the IL of interest, adjacent to a stationary ILvapor interface. Switching from dry $\mathrm{N}_{2}$ gas to $\mathrm{H}_{2} \mathrm{O}$-laden $\mathrm{N}_{2}$ (75\% relative humidity) initiates $\mathrm{H}_{2} \mathrm{O}$ absorption into the IL; switching back to dry $\mathrm{N}_{2}$ initiates desorption.

\section{A. Analysis of spatiotemporal concentration profiles}

We extract the composition-dependent diffusivity $D\left(c_{\mathrm{H}_{2} \mathrm{O}}\right)$ from measured profiles $c_{\mathrm{H}_{2} \mathrm{O}}(y, t)$ by solving the diffusion-advection equation

$$
\frac{\partial c_{\mathrm{H}_{2} \mathrm{O}}}{\partial t}=\frac{\partial}{\partial y}\left(D\left(c_{\mathrm{H}_{2} \mathrm{O}}\right) \frac{\partial c_{\mathrm{H}_{2} \mathrm{O}}}{\partial y}\right)-v^{0} \frac{\partial c_{\mathrm{H}_{2} \mathrm{O}}}{\partial y}
$$

in MATLAB, starting with an assumed mathematical form for $D\left(c_{\mathrm{H}_{2} \mathrm{O}}\right)$ and then iteratively adapting it to minimize the sum of squared differences between measurements and solutions to Eq. (3). The final (advective) term in Eq. (3) reflects the volumetric flux of water sorbed into the IL.

The high-resolution $\mu$ FPI data therefore allow a quantitative comparison of different functional forms of this composition dependence. A statistical analysis of multiple diffusivity functionals is provided in Appendix E. Ultimately, the high-resolution concentration profiles reveal the diffusivity of ILs studied to depend exponentially on water mole fraction

$$
x_{\mathrm{H}_{2} \mathrm{O}}=\frac{n_{\mathrm{H}_{2} \mathrm{O}}}{n_{\mathrm{H}_{2} \mathrm{O}}+n_{\mathrm{IL} \text { pair }}},
$$

via

$$
D\left(x_{\mathrm{H}_{2} \mathrm{O}}\right)=D_{0} \exp \left(\alpha x_{\mathrm{H}_{2} \mathrm{O}}\right) .
$$

Equation (5) gives excellent agreement between the measured values and model fits (Fig. 1). The infinite dilution diffusivity $D_{0}$ and the exponential modifier $\alpha$ are the only fitting parameters in Eqs. (3) and (5). It is worth emphasizing that a single $\mu$ FPI experiment probes the diffusivity over a continuous IL- $\mathrm{H}_{2} \mathrm{O}$ composition range (see the lines in Fig. 2), bracketed between the "neat" IL and the concentration formed at vapor-solution equilibrium.

An alternative method to determine $D(c)$ involves converting each measured concentration profile to a local diffusivity by numerically solving (3) without enforcing a functional form (see Ref. [65]). Although less precise due to numerical smoothing of the profiles, the exponential dependence on $x_{\mathrm{H}_{2} \mathrm{O}}$ is retained.

\section{INFLUENCE OF ANION, CATION, AND TEMPERATURE}

The ease with which a single $\mu$ FPI measurement can be used to generate an entire concentration-dependent diffusivity relationship allows detailed investigation of the effects of ion selection on solute diffusion within this class of ILs (Fig. 2). In general, we find that the exponentially dependent diffusivities given by Eq. (5) accurately describe alkylmethylimidazolium-halide $\mathrm{IL}-\mathrm{H}_{2} \mathrm{O}$ mixtures (associated profiles are provided in Appendix E). Furthermore, this combination of measurements elucidates the effect of anion and cation chemistry on the diffusion parameters $D_{0}$ 


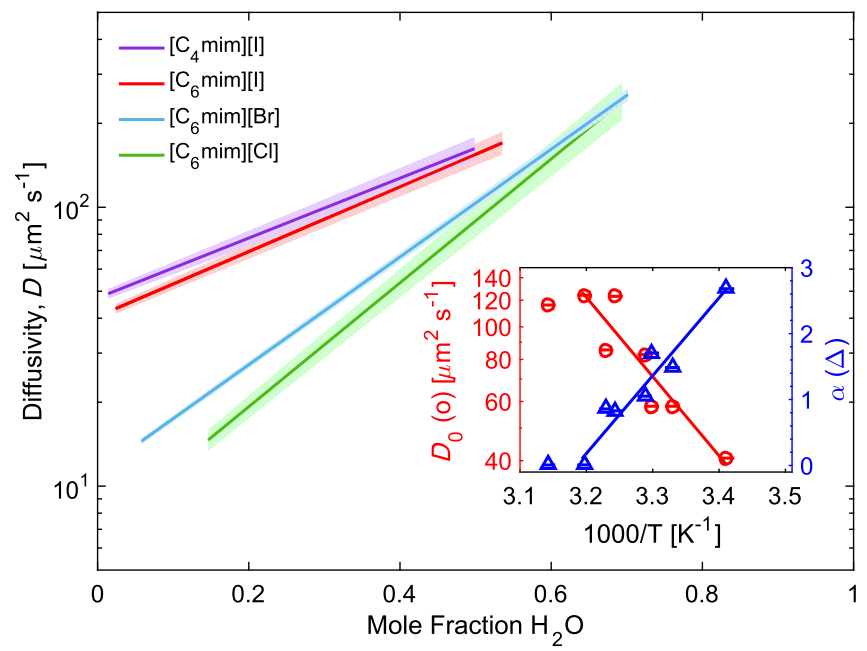

FIG. 2. Microfluidic interferometry measurements reveal the ubiquity of the exponential composition dependence over a range of ILs and temperatures. Room-temperature diffusivities measured in multiple alkylmethylimidazolium-halide $\mathrm{IL}-\mathrm{H}_{2} \mathrm{O}$ mixtures show $D_{0}$ decreases and $\alpha$ increases with increasing anion electronegativity. The error in fit is indicated by shading. Measurements performed over $20^{\circ}-40^{\circ} \mathrm{C}$ in $\left[\mathrm{C}_{6} \mathrm{mim}\right][\mathrm{I}]-\mathrm{H}_{2} \mathrm{O}$ mixtures (inset) reveal that $D_{0}$ scales Arrheniusly and $\alpha \sim 1 / T$.

and $\alpha$ (Table I). For example, for $\left[\mathrm{C}_{6} \mathrm{mim}\right][\mathrm{X}]$, we find that $D_{0}$ decreases with increasing anion $\left(X^{-}\right)$electronegativity $\left(D_{0, \mathrm{I}}>D_{0, \mathrm{Br}}>D_{0, \mathrm{Cl}}\right)$, whereas $\alpha$ increases with increasing electronegativity $\left(\alpha_{\mathrm{I}}<\alpha_{\mathrm{Br}}<\alpha_{\mathrm{Cl}}\right)$. By comparison, a modification of the nonpolar alkyl group of the imidazolium cation, probed here by comparing $\left[\mathrm{C}_{4} \mathrm{mim}\right][\mathrm{I}]$ and $\left[\mathrm{C}_{6} \mathrm{mim}\right][\mathrm{I}]$, appears to have no significant influence on the measured diffusivity.

The incorporation of temperature control with the $\mu \mathrm{FPI}$ device (details provided in Appendix B) allows experiments to probe the temperature dependence of the measured concentration-dependent diffusivity. Representative results for $\left[\mathrm{C}_{6} \mathrm{mim}\right][\mathrm{I}]$ are summarized in Fig. 2 (inset). We find an approximate Arrhenius dependence of $D_{0}$ (i.e., $\ln D_{0} \sim 1 / T$ ), whereas $\alpha$ appears to vary as $\sim 1 / T$. Interestingly, $\alpha$ vanishes at $T \sim 313 \mathrm{~K}$, indicating that the diffusivity no longer depends on the composition at sufficiently high temperatures.

Taken together, these results identify the electronegativity of the anion to be an important determining factor in setting the magnitude of the diffusivity, as well as its composition

TABLE I. $\mathrm{H}_{2} \mathrm{O}$ diffusivity parameters in various ILs at ambient temperature.

\begin{tabular}{lccc}
\hline \hline Ionic liquid & $D_{0}\left(\mu \mathrm{m}^{2} \mathrm{~s}^{-1}\right)$ & $\alpha$ & $x_{\mathrm{H}_{2} \mathrm{O}}$ range \\
\hline$\left[\mathrm{C}_{4} \mathrm{mim}\right][\mathrm{I}]$ & $47 \pm 2$ & $2.5 \pm 0.1$ & $0.014-0.499$ \\
{$\left[\mathrm{C}_{6} \mathrm{mim}\right][\mathrm{I}]$} & $41 \pm 2$ & $2.7 \pm 0.1$ & $0.024-0.535$ \\
{$\left[\mathrm{C}_{6} \mathrm{mim}\right][\mathrm{Br}]$} & $11.2 \pm 0.3$ & $4.45 \pm 0.04$ & $0.058-0.702$ \\
{$\left[\mathrm{C}_{6} \mathrm{mim}\right][\mathrm{Cl}]$} & $7.0 \pm 0.5$ & $5.1 \pm 0.1$ & $0.146-0.694$ \\
\hline \hline
\end{tabular}

dependence, in the water-alkylmethylimidazolium-halide system. Furthermore, they provide strong evidence for the hypothesized role of IL-solute interactions in the discussion to follow. Interestingly, for all cations and anions, $\mathrm{H}_{2} \mathrm{O}$ diffusivities appear to converge near $x_{\mathrm{H}_{2} \mathrm{O}}=0.7$ when extrapolated, which might reflect a composition where a discontinuous structural or physicochemical transition occurs. Similar transitions are observed in other solute-IL pairs, including $\mathrm{H}_{2} \mathrm{O}$ in $\left[\mathrm{C}_{4} \mathrm{mim}\right]\left[\mathrm{BF}_{4}\right]$ [53], and for propylene in $\left[\mathrm{C}_{4} \mathrm{C}_{1} \mathrm{Pyrr}\right]\left[\mathrm{NTF}_{2}\right][66,67]$ near $x_{\text {solute }}=0.7$. However, even if such a transition occurs in the systems in the current study, it would be insufficient to explain the observed composition-dependent behavior over the broad $x_{\mathrm{H}_{2} \mathrm{O}}<0.7$ range.

\section{COMPARISON OF DIFFUSIVITIES: MICROFLUIDIC INTERFEROMETRY, PFGNMR, AND STOKES-EINSTEIN PREDICTION}

To better inform hypotheses for the origin of the observed exponential dependence of diffusivity on IL- $\mathrm{H}_{2} \mathrm{O}$ composition, we compare the results obtained by $\mu$ FPI to more conventional diffusivity measurements and models including PFGNMR and the Stokes-Einstein relation. Here, we choose to focus in detail on the $\left[\mathrm{C}_{6} \mathrm{mim}\right][\mathrm{I}]-\mathrm{H}_{2} \mathrm{O}$ mixture as a representative example, although comparisons for $\left[\mathrm{C}_{6} \operatorname{mim}\right][\mathrm{Cl}]-\mathrm{H}_{2} \mathrm{O}$ mixtures are also given in Appendix $\mathrm{F}$.

First, we validate the $\mathrm{H}_{2} \mathrm{O}$ diffusivities extracted from $\mu$ FPI using conventional ${ }^{1} \mathrm{H}$ PFGNMR. Species diffusivities in multiple $\mathrm{H}_{2} \mathrm{O}$-IL mixtures of variable compositions are measured according to the protocol described in Appendix F. Figure 3 shows quantitative agreement between the $\mathrm{H}_{2} \mathrm{O}$ diffusivities measured in $\left[\mathrm{C}_{6} \mathrm{mim}\right][\mathrm{I}]$ using PFGNMR and $\mu$ FPI. This agreement validates the results of the $\mu$ FPI method and further reinforces the exponential dependence of diffusivity on $x_{\mathrm{H}_{2} \mathrm{O}}$. By contrast, ${ }^{1} \mathrm{H}$ PFGNMR measurements of the $\left[\mathrm{C}_{6} \mathrm{mim}\right]^{+}$cation diffusivity are smaller than the $\mathrm{H}_{2} \mathrm{O}$ diffusivity by an order of magnitude; a similar discrepancy in diffusivities has also been measured in PFGNMR studies on methylimidazolium $\mathrm{IL}-\mathrm{H}_{2} \mathrm{O}$ mixtures [55-58]. As with $\mathrm{H}_{2} \mathrm{O}$, the cation diffusivity increases with increasing $\mathrm{H}_{2} \mathrm{O}$ content, although the difference in magnitude between the water and cation is preserved over the measured concentration range. In the context of the $\mu$ FPI measurements, this result indicates that the collective, gradient-driven diffusion during water sorption is dominated by the relatively fast dynamics of the water solute.

One might hope that the Stokes-Einstein relation [Eq. (1)] would be accurate for the systems under study and so would successfully capture the composition-dependent diffusivity. After all, IL viscosity decreases with increasing $\mathrm{H}_{2} \mathrm{O}$ content; all species diffusivities should increase accordingly. Indeed, the SE relation accurately predicts the cation diffusivities using the measured mixture viscosity and cation dimensions of $4 \times 6 \times 15 \AA$ based on the van der Waals radii of constituent atoms (Fig. 3). However, the SE relation fails 


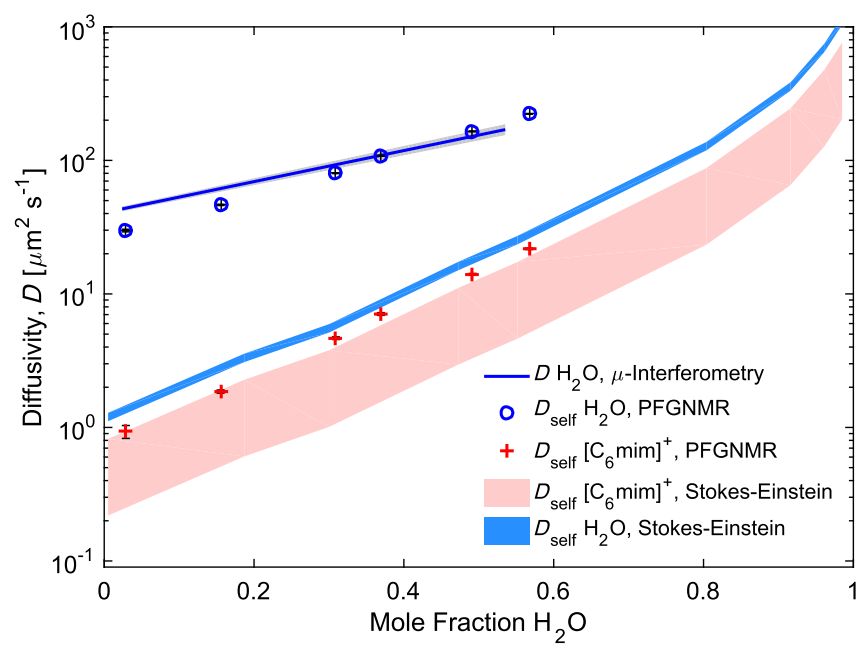

FIG. 3. Measured diffusivities of species in $\left[\mathrm{C}_{6} \mathrm{mim}\right][\mathrm{I}]-\mathrm{H}_{2} \mathrm{O}$ mixtures at an ambient temperature. The line denotes the continuous diffusivity functional measured by $\mu$ FPI. Points denote diffusivities measured by PFGNMR in equilibrium mixtures. Error bars are smaller than the markers. Blue and pink bands denote diffusivities of $\mathrm{H}_{2} \mathrm{O}$ and $\left[\mathrm{C}_{6} \mathrm{mim}\right]^{+}$computed from the Stokes-Einstein relation, respectively. The failure of $D_{\mathrm{SE}}$ for $\mathrm{H}_{2} \mathrm{O}$ suggests noncontinuum mechanisms for $\mathrm{H}_{2} \mathrm{O}$ transport.

dramatically for $\mathrm{H}_{2} \mathrm{O}$, underpredicting the diffusivities by more than an order of magnitude. This failure immediately reveals that $\mathrm{H}_{2} \mathrm{O}$ does not move through the IL as through a continuum fluid but instead follows a qualitatively different transport mechanism.

\section{MICROSCOPIC ORIGIN OF THE FAILURE OF STOKES-EINSTEIN AND DIFFUSIVITIES' EXPONENTIAL COMPOSITION DEPENDENCE}

The failure of the SE relation begs the question: What microscopic features prevent $\mathrm{H}_{2} \mathrm{O}$ from experiencing the IL as a continuum? A more accurate diffusion mechanism must capture the anomalous high diffusivities that SE underpredicts and, additionally, account for the observed concentration dependence of the solute diffusivity. We posit two distinct possibilities capable of accommodating the observed phenomena. First, alkylmethylimidazoliumhalide ILs are known to self-assemble into heterogeneous polar (charge-rich) and nonpolar (charge-poor) domains. This mesostructure might undergo significant or discontinuous changes with increasing water content, e.g., thereby changing path tortuosities or connectivities experienced by diffusing solutes in these domains. Second, IL-solute interactions might enable water to diffuse through the IL mesostructure by a process that does not require ions to reorganize. Both cases diverge from Stokes-Einstein: Solutes diffuse without forcing the IL matrix and its mesostructure to flow and rearrange. The macroscopically measured IL viscosity $\eta$, on the other hand, inherently reflects such rearrangements-and thus becomes effectively decoupled from solute diffusivity.
The following experiments test whether one, if either, of the proposed cases accounts for all of the concentrationdependent diffusivity. While both mesostructure and ILsolute interactions may change with the solute content, our aim is to identify a dominant contributor in order to better inform IL design strategies aimed at fast solute diffusion.

\section{A. IL mesostructure}

To evaluate the potential influence of mesostructure changes, we use scattering to compare structural features over the broad composition range probed in $\mu$ FPI experiments. Previously, Yamamuro et al. used neutron diffraction to show that $\left[\mathrm{C}_{8} \mathrm{mim}\right][\mathrm{Cl}]$, an IL related to those studied here, forms a network of polar regions that have three characteristic domain spacings [47] attributed (in order of decreasing distance) to the separation between polar ionic regions, the distance between adjacent ions within the regions, and interatomic spacing within the alkyl chains located within the nonpolar domains [68]. Similarly, our wide-angle x-ray scattering (WAXS) measurements on $\left[\mathrm{C}_{6} \mathrm{mim}\right][\mathrm{Cl}]-\mathrm{H}_{2} \mathrm{O}$ mixtures (Fig. 4) reveal these three domains to be qualitatively preserved over the entire $x_{\mathrm{H}_{2} \mathrm{O}}=0.09-0.69$ composition space probed in $\mu$ FPI experiments. Our WAXS results are consistent with combined XRD and MD simulations reported by Borodin et al. for $\left[\mathrm{C}_{8} \mathrm{mim}\right]\left[\mathrm{BF}_{4}\right]-\mathrm{H}_{2} \mathrm{O}$ mixtures [69]. Gaussian fits to the peaks centered at $0.3,1.0$, and $1.6 \AA^{-1}$ provide reasonable fits to the data and are quantitatively similar to the $0.3,1.1$, and $1.4 \AA^{-1}$ reported by Yamamuro for neat $\left[\mathrm{C}_{8} \mathrm{mim}\right][\mathrm{Cl}]$ [47]. These peaks correspond to domains of spacings $d=2 \pi / q$ plotted in Fig. 4(b), which seem reasonable given the molecular dimensions of the cation. While the measurements do not distinguish between discrete polar aggregates or a bicontinuous phase, the structure shows no significant variation with $\mathrm{H}_{2} \mathrm{O}$. In the $\left[\mathrm{C}_{6} \operatorname{mim}\right][\mathrm{Cl}] / \mathrm{H}_{2} \mathrm{O}$ mixtures studied here, domains swell by $6 \%$ for a wide range of water fractions $\left(0.09 \leq x_{\mathrm{H}_{2} \mathrm{O}} \leq\right.$ 0.69 ), which accounts for only a fraction of the $1600 \%$ increase in the measured diffusivity. Changes in $\mathrm{H}_{2} \mathrm{O}$
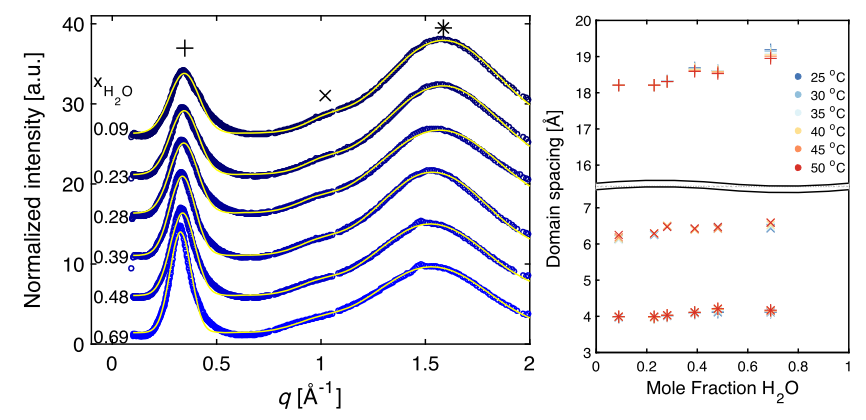

FIG. 4. (a) WAXS spectra of $\left[\mathrm{C}_{6} \mathrm{mim}\right][\mathrm{Cl}]-\mathrm{H}_{2} \mathrm{O}$ mixtures $\left(25^{\circ} \mathrm{C}\right.$ shown; spectra over $30^{\circ}-50^{\circ} \mathrm{C}$ are provided in Appendix G). Curves are shifted for clarity. Fitting the spectra to a sum of three Gaussians (yellow line) yields domain spacings plotted in (b) which are preserved over a broad composition range. 
diffusion thus are not due to slight changes in structural morphology but rather are dominated by the kinetics of transport.

\section{B. IL-solute interactions}

The very slight dependence of IL mesostructure spacing on the water content suggests that changes in IL-solute interaction energies are the primary source of composition dependence of the diffusivity. To evaluate this hypothesis more closely, we examine local interactions with water and the ions in our system using ${ }^{1} \mathrm{H}$ NMR. Differences in soluteion interactions, particularly hydrogen bonding strength, are implicated in composition-dependent ultrafast dynamics of solutes. In methylimidazolium $\left[\mathrm{NTf}_{2}\right]^{-}$and $\left[\mathrm{BF}_{4}\right]^{-} \mathrm{ILs}, 2 \mathrm{D}$ IR spectroscopy studies show that small molecular solutes (e.g., water, methanol, and ethanol) form hydrogen bonds with ions at high concentrations, ultimately affecting $\sim \mathcal{O}(10 \mathrm{ps})$ molecular reorientation timescales [70-72]. In methylimidazolium-halide ILs, combined deuterium exchange NMR, Fourier transform infrared spectroscopy, and molecular dynamics simulation studies have established that halide ions hydrogen bond strongly with the acidic $\mathrm{H} 2$ proton on the imidazolium ring [Fig. 5(a)] [73-78]. Our measurements of relative NMR chemical shifts reveal this local hydrogen bonding to be weakened by increasing $\mathrm{H}_{2} \mathrm{O}$ concentration: Figure 5(a) shows the full NMR spectra of two $\left[\mathrm{C}_{6} \mathrm{mim}\right][\mathrm{I}]-\mathrm{H}_{2} \mathrm{O}$ mixtures, and Figs. 5(b)-5(d) show the change in shift of specific protons as a function of $x_{\mathrm{H}_{2} \mathrm{O}}$. The most acidic $\mathrm{H} 2$ proton shifts upfield with the water contentindicating weakening $\mathrm{H}$-bonding - with an approximately linear dependence on $x_{\mathrm{H}_{2} \mathrm{O}}$. By contrast, $\mathrm{H} 7$ protons located on the apolar alkyl tail experience negligible shifts with $\mathrm{H}_{2} \mathrm{O}$, indicating that $\mathrm{H}_{2} \mathrm{O}$ has a strong local interaction with the

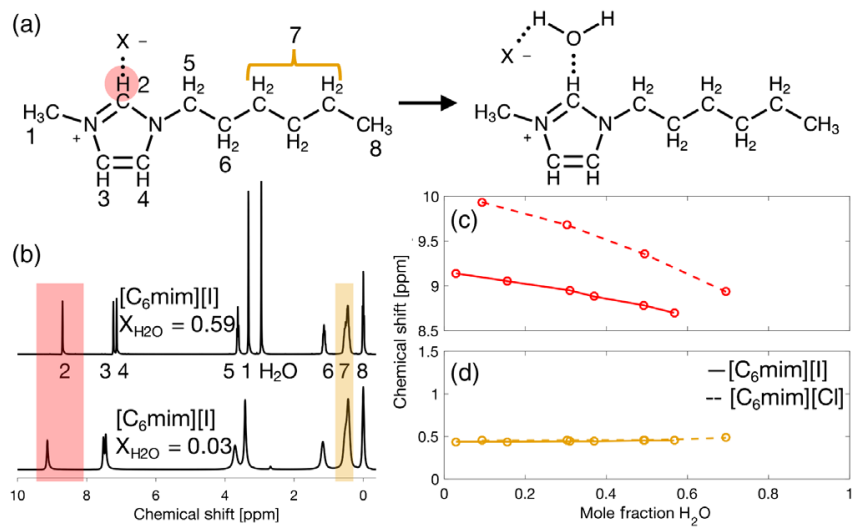

FIG. 5. Relative NMR chemical shifts indicate local hydrogen bonding increases with halide electronegativity but decreases approximately linearly with increasing water content. (a) Water screens hydrogen bonding between halide and the $\mathrm{H} 2$ proton. (b) Peaks of protons labeled in characteristic NMR spectra of $\left[\mathrm{C}_{6} \mathrm{mim}\right][\mathrm{I}]-\mathrm{H}_{2} \mathrm{O}\left(x_{\mathrm{H}_{2} \mathrm{O}}=0.03,0.57\right)$ mixtures. For $\left[\mathrm{C}_{6} \mathrm{mim}\right][\mathrm{I}]$ and $\left[\mathrm{C}_{6} \mathrm{mim}\right][\mathrm{Cl}]$, chemical shifts of the $\mathrm{H} 2(\mathrm{c})$ and $\mathrm{H} 7(\mathrm{~d})$ protons illustrate local $\mathrm{H}_{2} \mathrm{O}$ head group interactions. polar head group and associated anion. Deuterium exchange experiments further confirm this specific interaction $[73,74]$.

NMR additionally provides qualitative information regarding the relative strength of hydrogen bonding, as previously characterized in depth for $\mathrm{H}_{2} \mathrm{O}$ methylimizalium-halide mixtures $[73,74,79]$. Examining $\mathrm{H} 2$ shifts in $\left[\mathrm{C}_{6} \mathrm{mim}\right][\mathrm{I}]-$ and $\left[\mathrm{C}_{6} \mathrm{mim}\right][\mathrm{Cl}]-\mathrm{H}_{2} \mathrm{O}$ mixtures shows that both the absolute shift, extrapolated to infinite dilution $x_{\mathrm{H}_{2} \mathrm{O}} \rightarrow 0$, and the magnitude of the $\mathrm{H}_{2} \mathrm{O}$-dependent upfield shift (i.e., the slope) are higher for the chloride IL. This result indicates that the strength of the hydrogen bonding increases with anion electronegativity.

\section{AN ACTIVATED HOPPING MODEL FOR WATER DIFFUSION IN ILS}

Water's local, variable interaction with the compositioninvariant IL mesostructure suggests a potential mechanism for water diffusion. Given that $\mathrm{H}_{2} \mathrm{O}$ has a strong affinity for the polar regions and that these regions are preserved over a wide composition space, we expect $\mathrm{H}_{2} \mathrm{O}$ to spend more time located within the polar regions than the nonpolar regions. Since the cations move an order of magnitude slower than $\mathrm{H}_{2} \mathrm{O}$, we approximate $\mathrm{H}_{2} \mathrm{O}$ diffusion occurring as a series of hops between relatively immobile, polar sites, akin to lattice diffusion in solids (Fig. 6) [80].

In the context of such a model, the invariance of the IL structure to the presence of water indicates that the observed exponential concentration dependence of the diffusivity cannot come from changes in the lattice organization over which water hopping takes place. Instead, we hypothesize that the changing diffusivity reflects changes in the hopping time. The timescale for hopping is found by solving a Kramers-type problem for an $\mathrm{H}_{2} \mathrm{O}$ molecule trapped in a local potential well, until it experiences a large enough thermal fluctuation to traverse an activation energy barrier and fall into a neighboring well. Such processes have characteristic timescales $\tau \sim \tau_{0} e^{E_{a} / k_{B} T}$, where $\tau_{0}$ is a timescale for each "attempt" (e.g., related to molecular vibration frequencies of the lattice) and $E_{a}$ is the height of

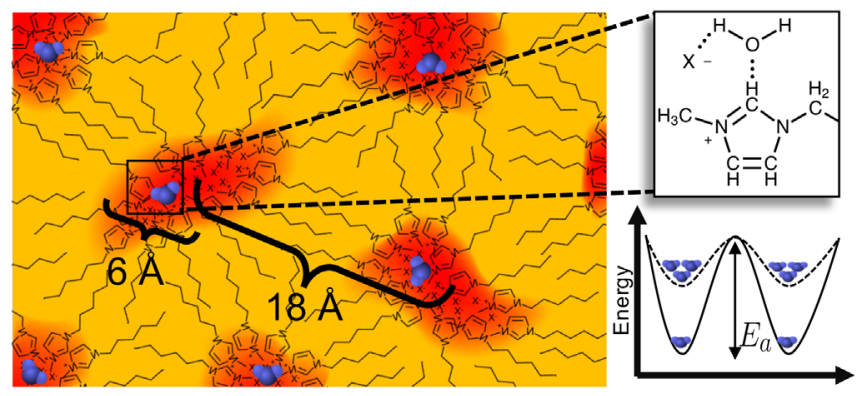

FIG. 6. Depiction of water intercalating within polar hopping sites. Whether the IL forms isolated aggregates (red regions) as depicted or a bicontinuous polar network, the sites do not rearrange for $\mathrm{H}_{2} \mathrm{O}$ to move. Instead, $\mathrm{H}_{2} \mathrm{O}$ hops between sites at a rate dictated by an activation energy. 
the activation energy barrier over which the molecule must diffuse [81]. With this timescale, we expect the diffusivity to have the form

$$
D\left(x_{\mathrm{H}_{2} \mathrm{O}}\right) \propto \frac{\lambda_{0}^{2}}{\tau_{0}} e^{-E_{a} / k_{B} T} .
$$

Here, we propose that the activation energy $E_{a}$ is intrinsically linked to the strength of hydrogen bonding between $\mathrm{H}_{2} \mathrm{O}$ and polar IL moieties. These hydrogen bonds must be disrupted for a water molecule to hop. Since measured NMR chemical shifts (Fig. 5) suggest this $\mathrm{H}$ bonding to decrease linearly with $x_{\mathrm{H}_{2} \mathrm{O}}$, we assume that $E_{a}$ decreases linearly with $x_{\mathrm{H}_{2} \mathrm{O}}$ according to

$$
E_{a}=E_{0}-E_{1} x_{\mathrm{H}_{2} \mathrm{O}}
$$

where $E_{0}$ is the intrinsic binding energy of the potential well at infinite dilution and $E_{1}$ captures the $\mathrm{H}_{2} \mathrm{O}$ composition dependence of the binding. Finite values of $E_{1}$ imply that each $\mathrm{H}_{2} \mathrm{O}$ molecule requires less energy to dissociate from its site when nearby $\mathrm{H}_{2} \mathrm{O}$ molecules screen the strength of hydrogen bonding at that site. Equation (7), in turn, predicts diffusivity to depend exponentially on $x_{\mathrm{H}_{2} \mathrm{O}}$, as measured interferometrically, and thus connects fitting parameters $D_{0}$ and $\alpha$ in the (empirical) functional form in Eq. (5) with H-bond characteristics via

$$
D_{0}=\frac{\lambda_{0}^{2}}{\tau_{0}} e^{-E_{0} / k_{B} T}
$$

and

$$
\alpha=E_{1} / k_{B} T .
$$

This activated hopping mechanism predicts relative diffusivities for different ILs depending on the strength of ILsolute interactions through Eq. (7). Based again on NMR, we expect $E_{0}$ and $E_{1}$ to increase with increasing anion electronegativity. This increase should manifest as a decrease in $D_{0}$ and an increase in $\alpha$. Indeed, the $\mu$ FPI measurements of different ILs (Fig. 2) show that $D_{0}$ decreases with increasing anion $\left(X^{-}\right)$electronegativity $\left(D_{0, \mathrm{I}}>D_{0, \mathrm{Br}}>D_{0, \mathrm{Cl}}\right)$ and $\alpha$ increases with increasing electronegativity $\left(\alpha_{\mathrm{I}}<\alpha_{\mathrm{Br}}<\alpha_{\mathrm{Cl}}\right)$. This result demonstrates the predictive capability of the hopping diffusion model.

The temperature-dependent diffusivity measurements (Fig. 2, inset) are additionally consistent with the activated hopping mechanism. WAXS measurements indicate that the IL mesostructure or the arrangement of polar sites is quantitatively preserved with increasing temperature over $25^{\circ}-50^{\circ} \mathrm{C}$ (Appendix G). Assuming that the activation energy for hopping, $E_{a}$, is given by the Gibbs free energy $\Delta G_{a}=\Delta H_{a}-T \Delta S_{a}$, we predict that the diffusivity should scale with the temperature according to

$$
D=\frac{\lambda_{0}^{2}}{\tau_{0}} e^{-S_{0} / k_{B}} e^{-H_{0} / k_{B} T} \exp \left[\left(\frac{H_{1}}{k_{B} T}-\frac{S_{1}}{k_{B}}\right) x_{\mathrm{H}_{2} \mathrm{O}}\right] .
$$

Comparing to Eq. (5), we therefore expect the infinite dilution diffusivity to have an Arrhenius dependence on the temperature:

$$
D_{0}(T) \sim e^{-H_{0} / k_{B} T},
$$

and the concentration-dependence factor $\alpha$ should vary linearly with the inverse temperature, via

$$
\alpha(T) \sim \frac{H_{1}}{k_{B} T}-\frac{S_{1}}{k_{B}} .
$$

These predictions are entirely consistent with measured values of $D_{0}(T)$ and $\alpha(T)$, as plotted in Fig. 2 over $20^{\circ}-40^{\circ} \mathrm{C}$. From the temperature-dependent measurements, we extract values of $H_{0}=18 k_{B} T, H_{1}=40 k_{B} T$, and $S_{1}=38 k_{B}$. Using Symmetry Adapted Perturbation Theory, Izgorodina et al. report total ion-pair interaction energies of -163 and $-170 k_{B} T$ for neat $\left[\mathrm{C}_{4} \mathrm{mim}\right][\mathrm{Br}]$ and $\left[\mathrm{C}_{4} \mathrm{mim}\right][\mathrm{Cl}]$, respectively [82]. This result suggests that the $\mathrm{H}_{2} \mathrm{O}$ interaction with the polar sites at infinite dilution is roughly an order of magnitude weaker than ion-ion binding. While it is impossible to decouple the impact of $S_{0}, \lambda_{0}$, and $\tau_{0}$ from these measurements alone, the combination $\left(\lambda_{0}^{2} / \tau_{0}\right) e^{-S_{0} / k_{B}}$-reflecting the contributions of lattice size, attempt frequency, and entropic penalties to the infinitedilution diffusivity - is found to be $0.004 \mathrm{~m}^{2} / \mathrm{s}$.

This activated hopping formalism is conceptually distinct, but nonetheless consistent, with Arrhenius behavior previously reported for $\mathrm{H}_{2} \mathrm{O}$ diffusion in equilibrium IL- $\mathrm{H}_{2} \mathrm{O}$ mixtures. By measuring diffusivities at different temperatures using PFGNMR, Menjoge et al. report that ion and $\mathrm{H}_{2} \mathrm{O}$ diffusivities scale as $D \propto \exp \left(-E_{a} / k_{B} T\right)$ [56]. Self-diffusion activation energies can be extracted from temperature experiments for different $\mathrm{H}_{2} \mathrm{O}$ compositions. Using such measurements, Fadeeva et al. find that $E_{a}$ decreases with increasing $x_{\mathrm{H}_{2} \mathrm{O}}$ content when comparing two mixtures of $\left[\mathrm{Pyrr}_{1,4}\right]\left[\mathrm{NTf}_{2}\right]-\mathrm{H}_{2} \mathrm{O}$ [58]. Menjoge et al. find that $E_{a}$ depends on $x_{\mathrm{H}_{2} \mathrm{O}}$ across five discrete compositions of $\left[\mathrm{C}_{2} \mathrm{mim}\right]\left[\mathrm{EtSO}_{4}\right]-\mathrm{H}_{2} \mathrm{O}$ and $\left[\mathrm{C}_{2} \mathrm{mim}\right][\mathrm{TFO}]-\mathrm{H}_{2} \mathrm{O}$ solutions; however, measured dependences are neither smooth nor monotonic. By measuring activation energies over a continuous composition space during gradientdriven transport, $\mu$ FPI allows us to more directly identify and construct mechanisms for the underlying composition and Arrhenius behavior and, thus, predict gradient-driven diffusion in other systems.

\section{CONCLUSION}

By measuring concentration gradient-driven solute absorption and desorption, microfluidic Fabry-Perot interferometry enables composition-dependent measurements of molecular diffusivities in IL-solvent mixtures. Combining these measurements with PFGNMR and WAXS analysis connects molecular and mesoscale structure to transport over industrially relevant length 
(millimeters) and time (tens of minutes) scales. Specifically, we find that water diffuses through alkylmethylimidazolium ILs much more quickly than the ions and faster than predicted by the Stokes-Einstein relation. Invoking the $\mathrm{SE}$ relation to predict $\mathrm{H}_{2} \mathrm{O}$ diffusivities fundamentally assumes that $\mathrm{H}_{2} \mathrm{O}$ molecules move by forcing the surrounding ionic mesostructure to flow and rearrange in the same way as during macroscopic viscosity measurements. As an alternative to this SE picture, we present a diffusive mechanism where $\mathrm{H}_{2} \mathrm{O}$ executes activated hops between polar ionic moieties that remain relatively immobile over the timescale of hopping. This mechanism provides a simple analytical model that quantitatively accounts for the effect of changes in solute concentration and IL ion selection through a binding energy. In the specific IL-water mixtures studied here, attractive interactions originate from hydrogen bonding between the solute and ions. Support for this hypothesis comes from complementary NMR measurements, which reveal that the strength of hydrogen bonding with acidic protons on the cation (i) weakens linearly with water mole fraction and (ii) strengthens with anion electronegativity. These trends predict the measured diffusivities' solute concentration dependence and ion dependence. As further support, the hopping mechanism predicts the measured temperature dependence of diffusivity at infinite dilution and at higher solute concentrations.

Although illustrated here for water, we believe a similar mechanism and model should apply to any small solute molecules that effectively "bind" to ions and that hop between binding sites more rapidly than the ions themselves rearrange. Altogether, our work indicates that chargesegregated mesostructure and local interactions in ionic liquids can have a dramatic effect on the mobility of neutral solutes, and provides simple principles to select IL constituents to facilitate the sorption and transport of specific solutes.

\section{ACKNOWLEDGMENTS}

We gratefully acknowledge helpful discussions with Arash Nowbahar, Douglas Vogus, Vincent Mansard, Baron Peters, and Florian Gebhard. A. V. B. was supported by the National Science Foundation (NSF) Graduate Research Fellowship (Grant No. DGE1144085). T. M. S., A. V. B., and S. H. acknowledge partial support from the NSF Materials Research Science and Engineering Center (MRSEC) Program through Division of Materials Research (DMR) 1720256 (IRG-2). A. V. B. and T. M. S. acknowledge partial support from the NSF through Division of Chemical, Bioengineering, Environmental and Transport Systems (CBET) 1438779. M. E. H. acknowledges partial support from the National Science Foundation under Grant No. CBET 1351371. Any opinion, findings, and conclusions or recommendations expressed in this material are those of the authors and do not necessarily reflect the views of the National Science Foundation. T. Ü. was funded by the DFG
Project No. BL231/49-1 and the German Academic Exchange Service Deutscher Akademischer Austauschdienst (DAAD) through its Thematic Network "ACalNet." The research reported here used shared facilities of the UCSB MRSEC (NSF DMR 1720256), the Microfluidics Facility within the California NanoSystems Institute, supported by UCSB and the University of California, Office of the President, and resources of the Advanced Light Source, which is a Department of Energy (DOE) Office of Science User Facility under Contract No. DE-AC02-05CH11231.

\section{APPENDIX A: MATERIALS: IONIC LIQUIDS}

Ionic liquids are purchased from Sigma-Aldrich ( $\left[\mathrm{C}_{6} \operatorname{mim}\right][\mathrm{Cl}] \geq 97 \%$ purity; all others $\geq 98 \%$ purity) and used without further purification. Prior to all experiments, ionic liquids are dried under a vacuum at $90^{\circ} \mathrm{C}$ for at least $24 \mathrm{~h}$. For refractive index measurements, PFGNMR measurements, and WAXS measurements, $\mathrm{IL}_{-} \mathrm{H}_{2} \mathrm{O}$ mixtures are prepared using ultrapure water (resistivity $18.2 \mathrm{M} \Omega \mathrm{cm}$ ). The $\mathrm{H}_{2} \mathrm{O}$ content of these mixtures is determined precisely through volumetric Karl Fischer titration. Dynamic viscosities of mixtures are measured using an Anton Paar densitometer with an inline falling ball viscometer (DMA $4100 \mathrm{M}$ ) at $25^{\circ} \mathrm{C}$ using a $2.5-\mathrm{mm}$ diameter capillary. The refractive indices of mixtures are measured using an Abbe refractometer.

\section{APPENDIX B: MICROFLUIDIC FABRY-PEROT INTERFEROMETRY}

Microfluidic Fabry-Perot interferometry is used to measure the dynamics of $\mathrm{H}_{2} \mathrm{O}$ sorption by ionic liquids. The microfluidic devices used here [Fig. 1(a)] consist of a single, $90 \mu \mathrm{m}$ layer of double-sided tape (permanent double sided tape, Scotch ${ }^{\circledR}$ ) sandwiched between semireflective slides. A computer-controlled laser cutter (Trotec Speedy 100) is used to cut the T-junction design into the tape. Slides are cut into $3 \times 4 \mathrm{~cm}^{2}$ pieces from sheets of mirrored acrylic prepared through vacuum metallization (1/8" acrylic see-through mirror, American Acrylics). The protective polyethylene film is removed from the sheets to prevent multiple layer interference. Holes are drilled through the slides to provide access for inlet and outlet tubing, which is secured to the device using epoxy.

Prior to filling, microfluidic devices and tubing are purged with $\mathrm{N}_{2}$ (purity 99.998\%) for $30 \mathrm{~min}$. ILs transferred from the vacuum oven are immediately injected into the stem of the microfluidic device. $\mathrm{N}_{2}$ is passed continuously through the vapor channel during injection and flows at $300 \mathrm{mBar}$ for an additional $30 \mathrm{~min}$ after injection to remove $\mathrm{H}_{2} \mathrm{O}$ absorbed during the syringe connection. The remaining IL is Karl Fischer titrated in order to determine the initial $\mathrm{H}_{2} \mathrm{O}$ content.

Bubbling $\mathrm{N}_{2}$ through $\mathrm{H}_{2} \mathrm{O}$ produces a vapor stream with $75 \%$ measured humidity. Precise control over vapor 
pressure is not required in this method, since the measured $\mathrm{H}_{2} \mathrm{O}$ content at the interface serves as a boundary condition in each experiment. Switching from pure $\mathrm{N}_{2}$ to the $\mathrm{H}_{2} \mathrm{O}$ laden stream initiates absorption of $\mathrm{H}_{2} \mathrm{O}$; switching back to $\mathrm{N}_{2}$ initiates desorption. Adjusting the inlet pressure from 300 to $700 \mathrm{mBar}$ maintains the position of the interface to within $\pm 6 \mu \mathrm{m}$.

For elevated temperature measurements, microfluidic devices are taped onto a dual Peltier-controlled thermal microscope stage (INSTEC, TSA02i). The chamber temperature is monitored with a thermocouple whose lead is attached to the midplane of the microfluidic device. Because of internal temperature gradients caused by the microscope objective opening, we measure temperature fluctuations of $\pm 1{ }^{\circ} \mathrm{C}$ during experiments. All other measurements are performed at ambient room temperature, $21.2 \pm 1.6^{\circ} \mathrm{C}$.

The concentration of $\mathrm{H}_{2} \mathrm{O}$ is measured at points within the device via multiple beam FECO interferometry. The optical configuration described by Vogus et al. [59] is used to acquire FECO every $1.92 \mu \mathrm{m}$ at $0.5 \mathrm{~Hz}$ over 20-30 min. A custom-written MATLAB code is used to track the relative shifts of fringes over position $y$ and time $t$, i.e., to identify the wavelength $\lambda_{m}^{F}$ that produces a maximum in transmitted light for a fringe of chromatic order $m$. These maxima are converted to changes in refractive indices using the relation

$$
n(y, t)=n\left(t_{0}\right) \frac{\lambda_{m}^{F}(y, t)}{\lambda_{m}^{F}\left(t_{0}\right)},
$$

where $n\left(t_{0}\right)$ denotes the refractive index of the initially uniform mixture. Drift due to device expansion is corrected by tracking small refractive index changes on the vapor side of the interface. Changes in the IL refractive index are converted to changes in concentration using calibration curves described in Appendix C.

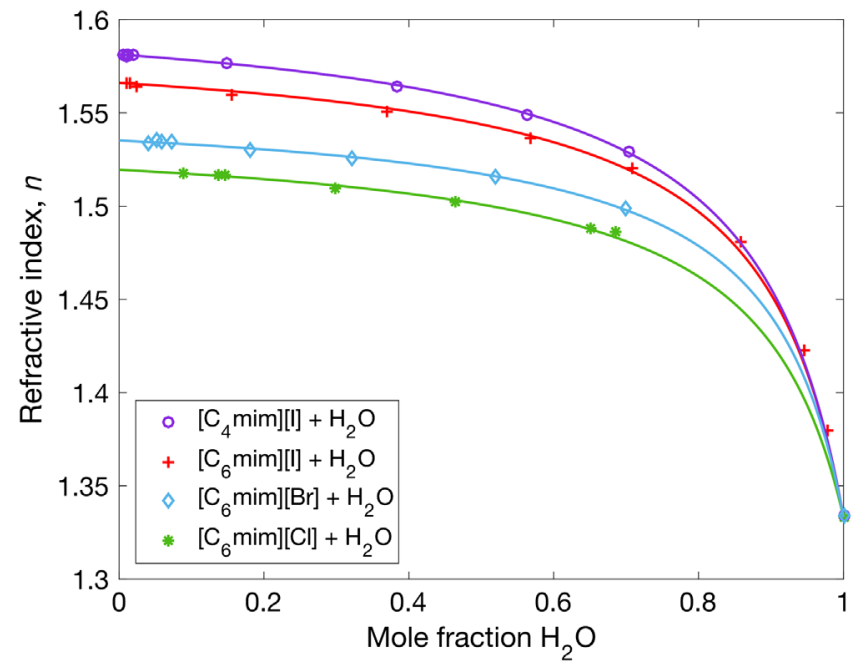

FIG. 7. Refractive indices of $\left[\mathrm{C}_{n} \mathrm{mim}\right][\mathrm{X}]-\mathrm{H}_{2} \mathrm{O}$ mixtures. Measured values (points) are fit to Eqs. (C1) and (C2).
TABLE II. Refractive index fitting parameters.

\begin{tabular}{lcc}
\hline \hline Ionic liquid & $\rho_{\mathrm{IL}}(\mathrm{g} / \mathrm{mL})$ & $n_{\mathrm{IL}}$ \\
\hline 1. $\left[\mathrm{C}_{4} \mathrm{mim}\right][\mathrm{I}]$ & 1.6764 & 1.5814 \\
2. $\left[\mathrm{C}_{6} \mathrm{mim}\right][\mathrm{I}]$ & 1.7183 & 1.5661 \\
3. $\left[\mathrm{C}_{6} \mathrm{mim}\right][\mathrm{Br}]$ & 1.5352 & 1.5352 \\
4. $\left[\mathrm{C}_{6} \mathrm{mim}\right][\mathrm{Cl}]$ & 1.2451 & 1.5195 \\
\hline \hline
\end{tabular}

\section{APPENDIX C: REFRACTIVE INDEX COMPOSITION CORRELATIONS}

Rilo et al. [64] report that the refractive indices $n_{\text {mixture }}$ of binary mixtures of ionic liquids with water and various alcohols scale linearly with the volume fraction of solute, or

$$
n_{\text {mixture }}=\phi_{\mathrm{H}_{2} \mathrm{O}} n_{\mathrm{H}_{2} \mathrm{O}}+\left(1-\phi_{\mathrm{H}_{2} \mathrm{O}}\right) n_{\mathrm{IL}} \text {, }
$$

where $\phi_{\mathrm{H}_{2} \mathrm{O}}$ is the volume fraction of $\mathrm{H}_{2} \mathrm{O}$ and $n_{i}$ is the refractive index of neat species $i$. Assuming the density is not a strong function of composition (ideal mixing), this relation can be written in terms of $x_{\mathrm{H}_{2} \mathrm{O}}$ using

$\phi_{\mathrm{H}_{2} \mathrm{O}}=\frac{x_{\mathrm{H}_{2} \mathrm{O}} M W_{\mathrm{H}_{2} \mathrm{O}} \rho_{\mathrm{IL}}}{x_{\mathrm{H}_{2} \mathrm{O}} M W_{\mathrm{H}_{2} \mathrm{O}} \rho_{\mathrm{IL}}+\left(1-x_{\mathrm{H}_{2} \mathrm{O}}\right) M W_{\mathrm{IL}} \rho_{\mathrm{H}_{2} \mathrm{O}}}$,

where $M W_{i}$ and $\rho_{i}$ are the molecular weight and density, respectively, of species $i$.

Figure 7 shows measured refractive indices of mixtures of $\mathrm{H}_{2} \mathrm{O}$ and the $\left[\mathrm{C}_{n} \operatorname{mim}\right][\mathrm{X}]$ ILs used in this study. The measured values are fit to Eqs. (C1) and (C2) by setting $\rho_{\mathrm{H}_{2} \mathrm{O}}=0.99704 \mathrm{~g} / \mathrm{mL}, n_{\mathrm{H}_{2} \mathrm{O}}=1.3332$, and leaving $\rho_{\mathrm{IL}}$ and $n_{\mathrm{IL}}$ as fitting parameters (Table II). Doing so provides a continuous correlation between the refractive index and $x_{\mathrm{H}_{2} \mathrm{O}}$, which is used to convert the local refractive index to composition.

\section{APPENDIX D: THEORETICAL BASIS FOR CONCENTRATION GRADIENT PROFILE ANALYSIS}

Microfluidic Fabry-Perot interferometry measures the spatiotemporal dependence of the $\mathrm{H}_{2} \mathrm{O}$ concentration during sorption. The composition-dependent diffusivity $D$ is extracted from measured concentration profiles by treating the sorption process as diffusion into a semi-infinite slab. The following derives the equations used to fit $c(y, t)$ from first principles. This section is adapted from Sec. 3.3.2 of Ref. [83].

Let the origin of the coordinate system $(y=0)$ be the liquid-vapor interface. The ionic liquid $\left[\mathrm{C}_{n} \mathrm{mim}\right][\mathrm{X}]$ occupies $y>0$; the vapor stream $y<0$. The mass balances on $\mathrm{H}_{2} \mathrm{O}$ and $\left[\mathrm{C}_{n} \operatorname{mim}\right][\mathrm{X}]$ are, respectively,

$$
\frac{\partial c_{1}}{\partial t}=-\frac{\partial}{\partial y}\left(\dot{N}_{1}\right)
$$

and 


$$
\frac{\partial c_{2}}{\partial t}=-\frac{\partial}{\partial y}\left(\dot{N}_{2}\right)
$$

For brevity, species 1 denotes $\mathrm{H}_{2} \mathrm{O}$; species 2 denotes $\left[\mathrm{C}_{n} \operatorname{mim}\right][\mathrm{X}]$. The flux of $\mathrm{H}_{2} \mathrm{O}, \dot{N}_{1}$, is the sum of diffusion and convection:

$$
\dot{N}_{1}=-D \frac{\partial c_{1}}{\partial y}+c_{1} v^{0}
$$

where the volume average velocity is

$$
v^{0}=\dot{N}_{1} \overline{V_{1}}+\dot{N}_{2} \overline{V_{2}} .
$$

In the equation above, $\overline{V_{i}}$ is the molar volume of species $i$.

The molar average velocity can be written in terms of concentration by enforcing mass conservation across the entire system. We assume that $\overline{V_{1}}$ and $\overline{V_{2}}$ are independent of the composition (ideal mixing), multiply Eqs. (D1) and (D2) by $\overline{V_{1}}$ and $\overline{V_{2}}$, and add to obtain

$$
\frac{\partial}{\partial t}\left(c_{1} \overline{V_{1}}+c_{2} \overline{V_{2}}\right)=-\frac{\partial}{\partial y}\left(\dot{N}_{1} \overline{V_{1}}+\dot{N}_{2} \overline{V_{2}}\right) .
$$

In the equation above, $c_{i} \overline{V_{i}}=\phi_{i}$ is the volume fraction of species $i$. The terms $c_{1} \overline{V_{1}}+c_{2} \overline{V_{2}}$ always sum to unity, making the left-hand side of the equation equal to 0 . Therefore, $\dot{N}_{1} \overline{V_{1}}+\dot{N}_{2} \overline{V_{2}}$ must be independent of $y$. Additionally, $\dot{N}_{2}$ is zero at the vapor interface, because the IL has negligible volatility. As such,

$$
\begin{aligned}
\dot{N}_{1} \overline{V_{1}}+\dot{N}_{2} \overline{V_{2}} & =\left.\overline{V_{1}} \dot{N}_{1}\right|_{y=0} \\
& =\overline{V_{1}}\left(-\left.D \frac{\partial c_{1}}{\partial y}\right|_{y=0}+\left.c_{1} \overline{V_{1}} \dot{N}_{1}\right|_{y=0}\right) .
\end{aligned}
$$

Solving Eq. (D7) for $\left.\overline{V_{1}} \dot{N}_{1}\right|_{y=0}$, we obtain

$$
\left.\overline{V_{1}} \dot{N}_{1}\right|_{y=0}=-\left.\left(\frac{D V_{1}\left(\partial c_{1} / \partial y\right)}{1-c_{1} \overline{V_{1}}}\right)\right|_{y=0}=v^{0} .
$$

Combining Eqs. (D1) and (D8) yields the governing equation for the concentration of $\mathrm{H}_{2} \mathrm{O}$ :

$\frac{\partial c_{1}}{\partial t}=\frac{\partial}{\partial y}\left(D \frac{\partial c_{1}}{\partial y}\right)+\left.\left(\frac{D \overline{V_{1}}\left(\partial c_{1} / \partial y\right)}{1-c_{1} \overline{V_{1}}}\right)\right|_{y=0} \frac{\partial c_{1}}{\partial y}$.

In the absorption and desorption experiments, the concentration at the interface $\left.c_{1}\right|_{y=0}$ changes with time. The diffusivity at the interface may be concentration dependent and, consequently, also changes with time. This being the case, $v^{0}$ is time dependent. To capture this dependence, we define a new characteristic dimensionless variable, a timedependent Peclet number:

$$
\mathrm{Pe}=\frac{L v^{0}}{\left.D\right|_{y=0}}=-\left.\left(\frac{L \overline{V_{1}}\left(\partial c_{1} / \partial y\right)}{1-c_{1} \overline{V_{1}}}\right)\right|_{y=0},
$$

where $L$ is the length interrogated by interferometry, approximately $1500 \mu \mathrm{m}$. Pe is the ratio of the characteristic timescale of convection to that of diffusion. With this definition, the $\mathrm{H}_{2} \mathrm{O}$ governing equation becomes

$$
\frac{\partial c_{1}}{\partial t}=\frac{\partial}{\partial y}\left(D \frac{\partial c_{1}}{\partial y}\right)-\frac{\left.D\right|_{y=0} \operatorname{Pe}}{L} \frac{\partial c_{1}}{\partial y} .
$$

To aid in numerical solving of the partial differential equation $y$ is nondimensionalized by $L$ as shown:

$$
\frac{\partial c_{1}}{\partial t}=\frac{1}{L^{2}} \frac{\partial}{\partial \tilde{y}}\left(D \frac{\partial c_{1}}{\partial \tilde{y}}\right)-\frac{\left.D\right|_{y=0} \operatorname{Pe}}{L^{2}} \frac{\partial c_{1}}{\partial \tilde{y}} .
$$

Pe gives an approximate measure of the relative magnitudes of convention and diffusion (approximate because $D$ does not necessarily equal $\left.D\right|_{y=0}$ throughout the $\mathrm{IL} / \mathrm{H}_{2} \mathrm{O}$ system). Pe can be measured directly from the experimental data by measuring the concentration and slope at the interface prior to model fitting. The insets in Fig. 1 show the time dependence of Pe for an example absorption and desorption experiment. During absorption, $\mathrm{Pe}$ is positive, reflecting that the volume-engendered convection is directed away from the interface. At an intermediate time $(t>600 \mathrm{~s})$, the gas stream is switched from humidified $\mathrm{N}_{2}$ to dry $\mathrm{N}_{2}$. When $\mathrm{H}_{2} \mathrm{O}$ is drawn out of the $\mathrm{IL}, \mathrm{Pe}<0, v^{0}$ is toward the interface. Pe is small but not vanishingly small. As such, we expect that including solute volume effects in the experimental fitting will have a small effect on the measured diffusivity.

A custom-written MATLAB code is used to extract a composition-dependent diffusivity $D\left(c_{\mathrm{H}_{2} \mathrm{O}}\right)$ from the profiles by iteratively solving Eq. (D12) and minimizing the sum of squared differences between the measured concentration and the theoretical concentration, $c_{\mathrm{H}_{2} \mathrm{O} \text {,theory }}(y, t)$, as a function of different diffusivity fitting parameters. The quality of fit measured by the residual sum of squares

$\delta=\frac{1}{N} \sum\left[c_{\mathrm{H}_{2} \mathrm{O} \text {,measured }}(y, t)-c_{\mathrm{H}_{2} \mathrm{O} \text {,theory }}(y, t)\right]^{2}$,

where $N$ is the number of concentration points measured. The high spatial and temporal resolution of these experiments makes $N \sim 700000$. For all numerical fits, boundary and initial conditions are as follows:

$$
\begin{gathered}
c_{1}(t, y=0)=\text { measured value, } \\
c_{1}(t, y=L)=0
\end{gathered}
$$

$c_{1}(t=0, y)=$ measured value $80 \mathrm{~s}$ after start of hydration.

For all experiments, IL molar volumes are those measured by Sastry, Vaghela, and Macwan [84]. In Table I, $D_{0}$ and $\alpha$ errors are $95 \%$ confidence intervals bounding at least four trials for each IL. 


\section{APPENDIX E: COMPARING THE ACCURACY OF DIFFERENT DIFFUSIVITY FUNCTIONS}

Here, we provide examples for fitting the PDE

$$
\frac{\partial c_{1}}{\partial t}=\frac{1}{L^{2}} \frac{\partial}{\partial \tilde{y}}\left(D \frac{\partial^{2} c_{1}}{\partial^{2} \tilde{y}}\right)-\frac{D P e}{L^{2}} \frac{\partial c_{1}}{\partial \tilde{y}}
$$

to the concentration profiles using different $D\left(c_{\mathrm{H}_{2} \mathrm{O}}\right)$ functional forms. The effect of including (excluding) solute volume considerations is also compared through fits with finite (zero) values of Pe.
Figures 8-10 show the profiles obtained for $\left[\mathrm{C}_{6} \mathrm{mim}\right][\mathrm{Cl}]$, $\left[\mathrm{C}_{6} \operatorname{mim}\right][\mathrm{Br}]$, and $\left[\mathrm{C}_{6} \mathrm{mim}\right][\mathrm{I}]$, respectively, using the different $D\left(c_{\mathrm{H}_{2} \mathrm{O}}\right)$. Only the finite Pe fits are shown for brevity. A cursory examination of the figures shows that the model $D=D_{0} \exp \left(\alpha x_{\mathrm{H}_{2} \mathrm{O}}\right)$ (where $D_{0}$ and $\alpha$ are fitting parameters) provides excellent agreement with the measured concentration in all cases and clearly superior agreement for $\left[\mathrm{C}_{6} \mathrm{mim}\right][\mathrm{Cl}]$ and $\left[\mathrm{C}_{6} \mathrm{mim}\right][\mathrm{Br}]$. For $\left[\mathrm{C}_{6} \mathrm{mim}\right][\mathrm{I}]$, the $\delta$ values must be examined to distinguish between the linear and exponential models.

Tables III-V give values of the normalized residual sum of squares, $\delta$, associated with those fits for $\left[\mathrm{C}_{6} \mathrm{mim}\right][\mathrm{Cl}]$,
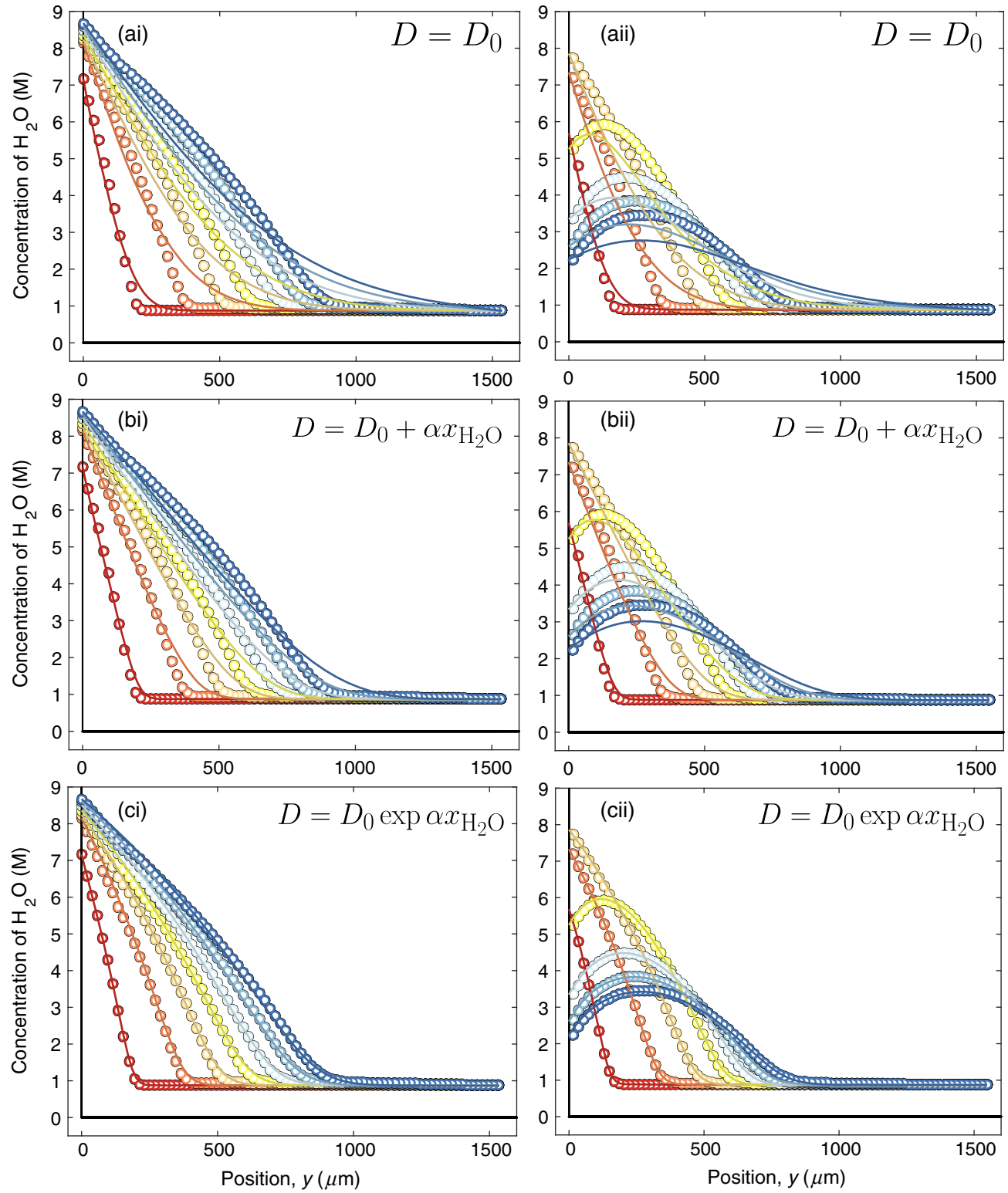

FIG. 8. Spatiotemporal concentration profiles of $\mathrm{H}_{2} \mathrm{O}$ (i) absorption and (ii) desorption by $\left[\mathrm{C}_{6} \mathrm{mim}\right][\mathrm{Cl}]$. Measured concentration values are demarked by circles. Every tenth point in space is included; other points are excluded for clarity. The numerical solution of Eq. (E1) with various $D\left(x_{\mathrm{H}_{2} \mathrm{O}}\right)$ finite Pe demarked by solid lines. (a) $D=D_{0}$; (b) $D=D_{0}+\alpha x_{\mathrm{H}_{2} \mathrm{O}}$; (c) $D=D_{0} \exp \left(\alpha x_{\mathrm{H}_{2} \mathrm{O}}\right)$. Time increases as colors change from red to blue with 4 min time intervals. 

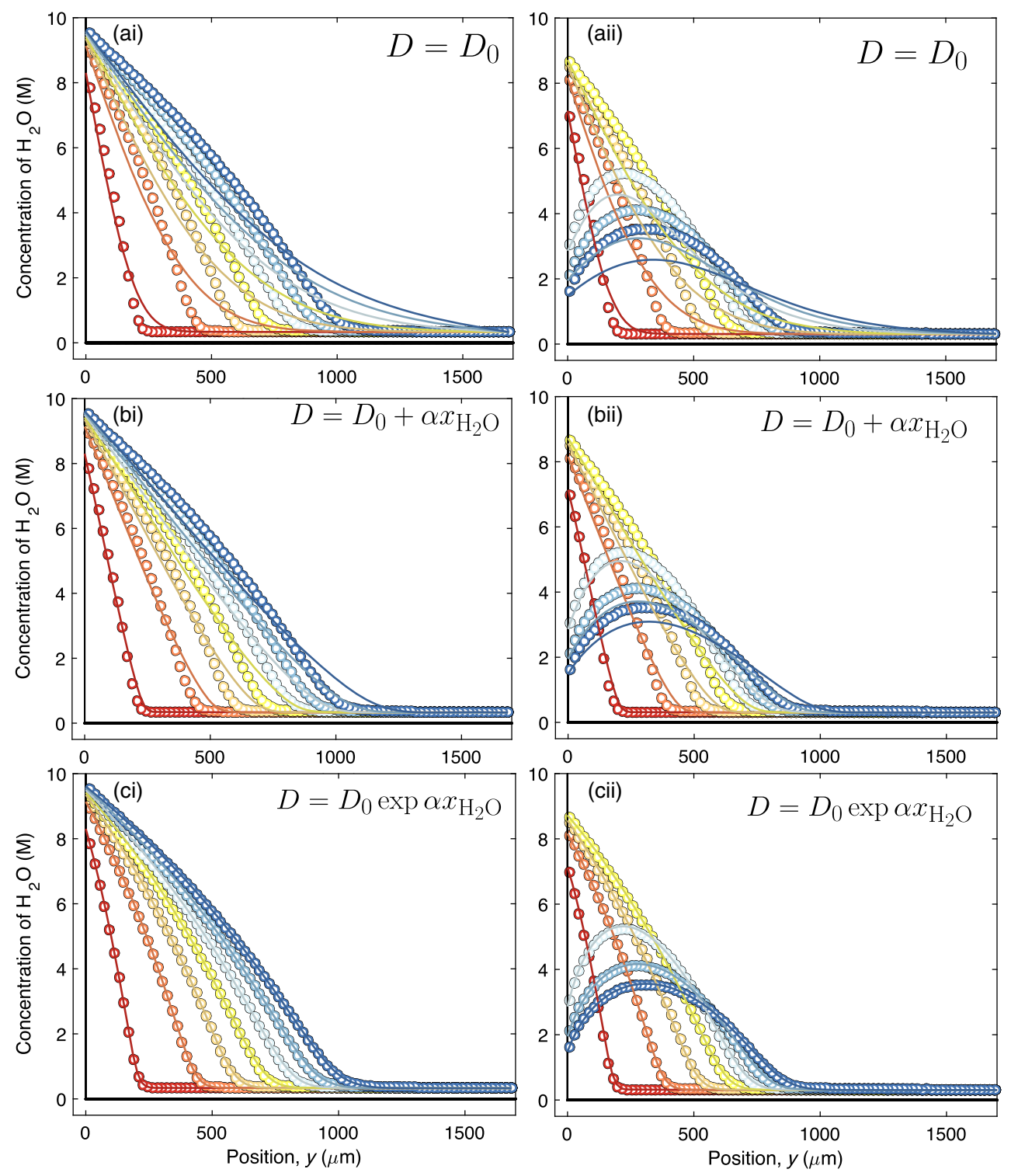

FIG. 9. Spatiotemporal concentration profiles of $\mathrm{H}_{2} \mathrm{O}$ (i) absorption and (ii) desorption by $\left[\mathrm{C}_{6}\right.$ mim] $][\mathrm{Br}]$. Measured concentration values are demarked by circles. Every tenth point in space is included; other points are excluded for clarity. The numerical solution of Eq. (E1) with various $D\left(x_{\mathrm{H}_{2} \mathrm{O}}\right)$ finite Pe demarked by solid lines. (a) $D=D_{0}$; (b) $D=D_{0}+\alpha x_{\mathrm{H}_{2} \mathrm{O}}$; (c) $D=D_{0} \exp \left(\alpha x_{\mathrm{H}_{2} \mathrm{O}}\right)$. Time increases as colors change from red to blue with 4 min time intervals.

$\left[\mathrm{C}_{6} \operatorname{mim}\right][\mathrm{Br}]$, and $\left[\mathrm{C}_{6} \mathrm{mim}\right][\mathrm{Cl}]$, respectively. Of the models shown, $D_{0} \exp \left(\alpha x_{\mathrm{H}_{2} \mathrm{O}}\right)$ provides the smallest value of $\delta$. Including Pe generally improves the quality of the fit but only marginally.

The residual sum of squares is used to perform an Akaike information criteria (AIC) test. The AIC test compares the quality of fits to one dataset with multiple fitting functions. The AIC value is calculated via

$$
\mathrm{AIC}=N \ln (\delta / N)+2 K,
$$

where $N$ is the number of observation in the dataset and $K$ is the number of fitting parameters in the function. The AIC test does not evaluate the absolute quality of the fit but instead compares relative accuracy. The $K$ term penalizes overfitting using models with excessive parameters. Models with better fits have lower AIC values. Tables III-V provide AIC values for the different case studies. The exponential model has the minimum AIC values by $10^{5}$ or more for $\left[\mathrm{C}_{6} \mathrm{mim}\right][\mathrm{Cl}],\left[\mathrm{C}_{6} \mathrm{mim}\right][\mathrm{Br}]$, and $\left[\mathrm{C}_{6} \mathrm{mim}\right][\mathrm{I}]$. Tables III-V also include frequently used goodness-of-fit parameters $\chi^{2}$ and $R^{2}$ :

$$
\chi^{2}=\frac{1}{N} \sum \frac{\left[c_{\mathrm{H}_{2} \mathrm{O}, \text { measured }}(y, t)-c_{\mathrm{H}_{2} \mathrm{O} \text {,theory }}(y, t)\right]^{2}}{c_{\mathrm{H}_{2} \mathrm{O}, \text { theory }}(y, t)},
$$



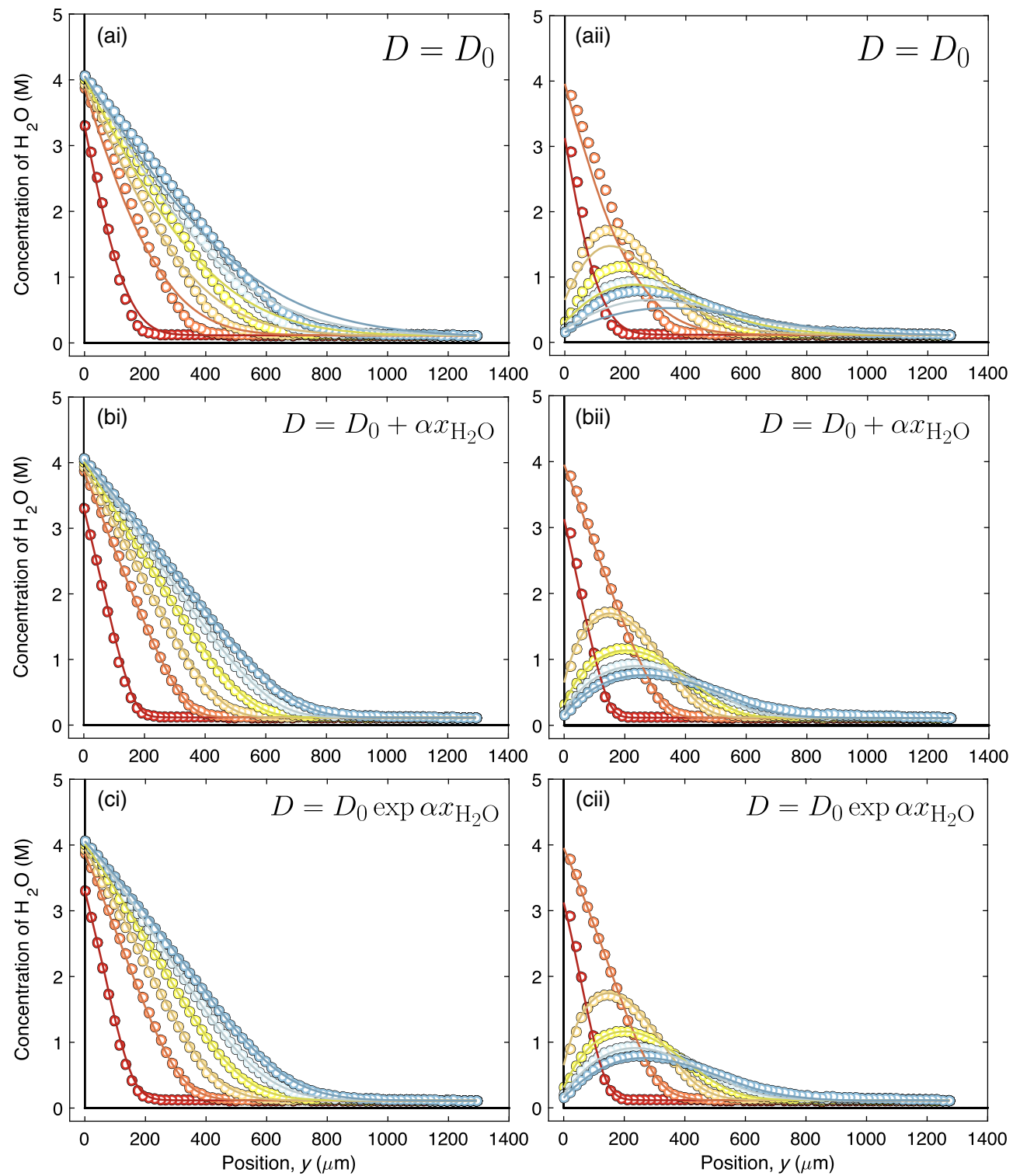

FIG. 10. Spatiotemporal concentration profiles of $\mathrm{H}_{2} \mathrm{O}$ (i) absorption and (ii) desorption by $\left[\mathrm{C}_{6} \mathrm{mim}\right][\mathrm{I}]$. Measured concentration values are demarked by circles. Every tenth point in space is included; other points are excluded for clarity. The numerical solution of Eq. (E1) with various $D\left(x_{\mathrm{H}_{2} \mathrm{O}}\right)$ finite Pe demarked by solid lines. (a) $D=D_{0}$; (b) $D=D_{0}+\alpha x_{\mathrm{H}_{2} \mathrm{O}}$; (c) $D=D_{0} \exp \left(\alpha x_{\mathrm{H}_{2} \mathrm{O}}\right)$. Time increases as colors change from red to blue with 3 min time intervals.

TABLE III. Comparison of diffusivity fits for $\left[\mathrm{C}_{6} \mathrm{mim}\right][\mathrm{Cl}]$.

\begin{tabular}{lclcccccc}
\hline \hline$D\left(x_{\mathrm{H}_{2} \mathrm{O}}\right)\left[\mu \mathrm{m}^{2} \mathrm{~s}^{-1}\right]$ & Pe & Process & $D_{0}$ & $\alpha$ & $\delta$ & AIC $\left(\times 10^{6}\right)$ & $\chi^{2}$ & $R^{2}$ \\
\hline$D_{0}$ & 0 & Absorption & 131.39 & $\ldots$ & 0.1834 & -2.18 & 0.0735 & 0.9681 \\
$D_{0}$ & 0 & Desorption & 108.28 & $\ldots$ & 0.1542 & -2.41 & 0.0632 & 0.9389 \\
$D_{0}$ & $\neq 0$ & Absorption & 118.81 & $\ldots$ & 0.1707 & -2.27 & 0.0683 & 0.9703 \\
$D_{0}$ & $\neq 0$ & Desorption & 104.41 & $\ldots$ & 0.1450 & -2.49 & 0.0601 & 0.9426 \\
$D_{0}+\alpha x_{\mathrm{H}_{2} \mathrm{O}}$ & 0 & Absorption & 0.00091 & 256.46 & 0.0575 & -3.66 & 0.0233 & 0.9900 \\
$D_{0}+\alpha x_{\mathrm{H}_{2} \mathrm{O}}$ & 0 & Desorption & 0.00199 & 239.43 & 0.0603 & -3.63 & 0.0237 & 0.9761 \\
$D_{0}+\alpha x_{\mathrm{H}_{2} \mathrm{O}}$ & $\neq 0$ & Absorption & 0.00204 & 233.05 & 0.0501 & -3.84 & 0.0217 & 0.9913 \\
$D_{0}+\alpha x_{\mathrm{H}_{2} \mathrm{O}}$ & $\neq 0$ & Desorption & 0.00072 & 226.01 & 0.0524 & -3.81 & 0.0209 & 0.9793 \\
$D_{0} \exp \left(\alpha x_{\mathrm{H}_{2} \mathrm{O}} \mathrm{O}\right.$ & 0 & Absorption & 9.89 & 4.69 & 0.0054 & -6.70 & 0.0024 & 0.99906 \\
$D_{0} \exp \left(\alpha x_{\mathrm{H}_{2} \mathrm{O}}\right)$ & 0 & Desorption & 5.20 & 6.04 & 0.0022 & -7.87 & 0.0012 & 0.99911 \\
$D_{0} \exp \left(\alpha x_{\mathrm{H}_{2} \mathrm{O}} \mathrm{O}\right.$ & $\neq 0$ & Absorption & 9.34 & 4.52 & 0.0055 & -6.69 & 0.0023 & 0.99905 \\
$D_{0} \exp \left(\alpha x_{\mathrm{H}_{2} \mathrm{O}} \mathrm{O}\right.$ & $\neq 0$ & Desorption & 5.78 & 5.64 & 0.0015 & -8.43 & 0.0007 & 0.99942 \\
\hline \hline
\end{tabular}


TABLE IV. Comparison of diffusivity fits for $\left[\mathrm{C}_{6} \mathrm{mim}\right][\mathrm{Br}]$.

\begin{tabular}{lclcccccc}
\hline \hline$D\left(x_{\mathrm{H}_{2} \mathrm{O}}\right)\left[\mu \mathrm{m}^{2} \mathrm{~s}^{-1}\right]$ & Pe & Process & $D_{0}$ & $\alpha$ & $\delta$ & AIC $\left(\times 10^{6}\right)$ & $\chi^{2}$ & $R^{2}$ \\
\hline$D_{0}$ & 0 & Absorption & 177.80 & $\ldots$ & 0.3437 & -1.54 & 0.1632 & 0.9621 \\
$D_{0}$ & 0 & Desorption & 119.78 & $\ldots$ & 0.2446 & -2.11 & 0.1211 & 0.9390 \\
$D_{0}$ & $\neq 0$ & Absorption & 161.85 & $\ldots$ & 0.3198 & -1.65 & 0.1547 & 0.9648 \\
$D_{0}$ & $\neq 0$ & Desorption & 118.21 & $\ldots$ & 0.2250 & -2.24 & 0.1167 & 0.9439 \\
$D_{0}+\alpha x_{\mathrm{H}_{2} \mathrm{O}}$ & 0 & Absorption & 0.00099 & 328.10 & 0.0934 & -3.42 & 0.0415 & 0.9897 \\
$D_{0}+\alpha x_{\mathrm{H}_{2} \mathrm{O}}$ & 0 & Desorption & 0.00164 & 256.24 & 0.0662 & -4.07 & 0.0301 & 0.9835 \\
$D_{0}+\alpha x_{\mathrm{H}_{2} \mathrm{O}}$ & $\neq 0$ & Absorption & 0.00176 & 291.67 & 0.0802 & -3.64 & 0.0366 & 0.9912 \\
$D_{0}+\alpha x_{\mathrm{H}_{2} \mathrm{O}}$ & $\neq 0$ & Desorption & 0.00072 & 238.23 & 0.0514 & -4.46 & 0.0240 & 0.9872 \\
$D_{0} \exp \left(\alpha x_{\mathrm{H}_{2} \mathrm{O}}\right)$ & 0 & Absorption & 13.52 & 4.41 & 0.0009 & -10.01 & 0.0008 & 0.99990 \\
$D_{0} \exp \left(\alpha x_{\mathrm{H}_{2} \mathrm{O}}\right)$ & 0 & Desorption & 9.85 & 4.76 & 0.0034 & -8.54 & 0.0026 & 0.99916 \\
$D_{0} \exp \left(\alpha x_{\mathrm{H}_{2} \mathrm{O}}\right)$ & $\neq 0$ & Absorption & 12.81 & 4.23 & 0.0012 & -9.69 & 0.0009 & 0.99987 \\
$D_{0} \exp \left(\alpha x_{\mathrm{H}_{2} \mathrm{O}}\right)$ & $\neq 0$ & Desorption & 10.82 & 4.37 & 0.0016 & -9.70 & 0.0012 & 0.99961 \\
\hline \hline
\end{tabular}

TABLE V. Comparison of diffusivity fits for $\left[\mathrm{C}_{6} \mathrm{mim}\right][\mathrm{I}]$.

\begin{tabular}{lclcccccc}
\hline \hline$D\left(x_{\mathrm{H}_{2} \mathrm{O}}\right)\left[\mu \mathrm{m}^{2} \mathrm{~s}^{-1}\right]$ & Pe & Process & $D_{0}$ & $\alpha$ & $\delta$ & AIC $\left(\times 10^{6}\right)$ & $\chi^{2}$ & $R^{2}$ \\
\hline$D_{0}$ & 0 & Absorption & 114.28 & $\ldots$ & 0.01816 & -2.82 & 0.0248 & 0.9868 \\
$D_{0}$ & 0 & Desorption & 92.72 & $\ldots$ & 0.01740 & -2.84 & 0.0278 & 0.9473 \\
$D_{0}$ & $\neq 0$ & Absorption & 109.26 & $\ldots$ & 0.01713 & -2.86 & 0.0234 & 0.9875 \\
$D_{0}$ & $\neq 0$ & Desorption & 91.43 & $\ldots$ & 0.01655 & -2.88 & 0.0267 & 0.9875 \\
$D_{0}+\alpha x_{\mathrm{H}_{2} \mathrm{O}}$ & 0 & Absorption & 17.24 & 284.86 & 0.00071 & -5.10 & 0.0013 & 0.9995 \\
$D_{0}+\alpha x_{\mathrm{H}_{2} \mathrm{O}}$ & 0 & Desorption & 14.14 & 288.33 & 0.000112 & -4.76 & 0.0034 & 0.9966 \\
$D_{0}+\alpha x_{\mathrm{H}_{2} \mathrm{O}}$ & $\neq 0$ & Absorption & 17.24 & 267.04 & 0.00066 & -5.15 & 0.0012 & 0.9995 \\
$D_{0}+\alpha x_{\mathrm{H}_{2} \mathrm{O}}$ & $\neq 0$ & Desorption & 16.12 & 270.48 & 0.00107 & -4.80 & 0.0033 & 0.9968 \\
$D_{0} \exp \left(\alpha x_{\mathrm{H}_{2} \mathrm{O}}\right)$ & 0 & Absorption & 37.49 & 2.96 & 0.00051 & -5.32 & 0.00056 & 0.99963 \\
$D_{0} \exp \left(\alpha x_{\mathrm{H}_{2} \mathrm{O}}\right)$ & 0 & Desorption & 30.56 & 3.52 & 0.00082 & -4.99 & 0.00220 & 0.99752 \\
$D_{0} \exp \left(\alpha x_{\mathrm{H}_{2} \mathrm{O}}\right)$ & $\neq 0$ & Absorption & 36.68 & 2.86 & 0.00054 & -5.29 & 0.00057 & 0.99961 \\
$D_{0} \exp \left(\alpha x_{\mathrm{H}_{2} \mathrm{O}}\right)$ & $\neq 0$ & Desorption & 31.96 & 3.27 & 0.00086 & -4.95 & 0.00217 & 0.99740 \\
\hline \hline
\end{tabular}

$R^{2}=1-\frac{\sum\left[c_{\mathrm{H}_{2} \mathrm{O}, \text { measured }}(y, t)-c_{\mathrm{H}_{2} \mathrm{O}, \text { theory }}(y, t)\right]^{2}}{\sum\left[c_{\mathrm{H}_{2} \mathrm{O} \text {,measured }}(y, t)-c_{\text {mean }}\right]^{2}}$,

where $c_{\text {mean }}$ is the mean water concentration over all of space and time.

\section{APPENDIX F: PULSED-FIELD GRADIENT NMR}

${ }^{1} \mathrm{H}$ NMR spectra and PFG diffusion experiments are acquired on a Bruker $300 \mathrm{MHz}$ Super-Wide Bore NMR spectrometer equipped with a AVIII console and a Bruker microimaging probe Micro 5 that offers a gradient strength of up to $3 \mathrm{~T} / \mathrm{m}$. The samples are sealed in $5 \mathrm{~mm}$ o.d. NMR tubes and kept at $25^{\circ} \mathrm{C}$ during the measurements.

For the PFG measurements, a bipolar stimulated echo sequence is used to compensate internal gradients caused by the sample. The gradient pulse length $\delta$ is kept at $1 \mathrm{~ms}$ and the time between the gradients, $\Delta$ (diffusion time), at $50 \mathrm{~ms}$ for all measurements. The PFGNMR experiments of the chloride sample are additionally performed with a $\Delta$ of $20 \mathrm{~ms}$ to check for diffusion time-dependent effects like convection. It is found that there is no dependence of self-diffusion coefficients on $\Delta$. For each diffusion dataset,
32 points (gradient steps) are acquired and the signal averaged over 16 scans.

The ${ }^{1} \mathrm{H}$ spectra and diffusion data are baseline and phase corrected by an in-house MATLAB routine. To analyze the relative cation's ${ }^{1} \mathrm{H}$ peak shifts for different water contents, the $\mathrm{H} 8$ proton is used as an internal reference to avoid nanostructure variations caused by an added reference. We note that NMR measurements performed on methylimidazolium-halide- $\mathrm{H}_{2} \mathrm{O}$ mixtures using external doublereference methods [73,74] reveal the same qualitative aspects about hydrogen bonding as in our measurements.

The diffusion coefficient of the ionic liquid's cation and the water component is determined by fitting a monoexponential decay to the integral of each peak of the spectroscopically resolved data according to the StejskalTanner equation $I=I_{0} e^{\left[\gamma^{2} G^{2} \delta^{2}(\Delta-\delta / 3) D\right]}$. The fit of the cation's protons results in the same diffusivity within the error margin, and the cation's total diffusion coefficient is calculated as the average of all these values.

Figure 11 shows the NMR spectra of $\left[\mathrm{C}_{6} \mathrm{mim}\right][\mathrm{Cl}]-\mathrm{H}_{2} \mathrm{O}$ at various $x_{\mathrm{H}_{2} \mathrm{O}}$. Peaks broaden as $x_{\mathrm{H}_{2} \mathrm{O}}$ due to the increase 


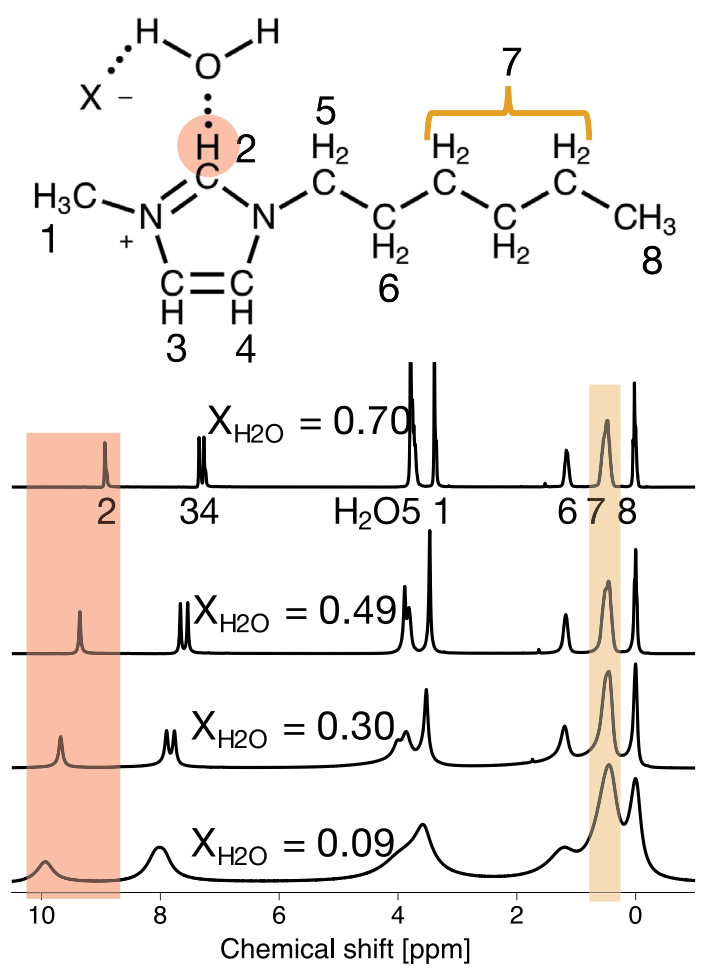

FIG. 11. Relative NMR chemical shifts indicate increasing local hydrogen bonding strength with decreasing water content. Water screens hydrogen bonding between halide and $\mathrm{H} 2$ proton. Peaks of protons labeled in characteristic NMR spectra of $\left[\mathrm{C}_{6} \operatorname{mim}\right][\mathrm{Cl}]-\mathrm{H}_{2} \mathrm{O}$ mixtures.

in viscosity, consistent with Ref. [74]. In addition to this broad nature, the overlap of the $\mathrm{H}_{2} \mathrm{O}$ peak with the $\mathrm{H} 5$ peak contributes to an error in the measured $\mathrm{H}_{2} \mathrm{O}$ diffusivity (Fig. 12) and even prevents it from being measured in the driest sample. These measurement challenges highlight the value of microfluidic interferometry.

\section{APPENDIX G: WIDE-ANGLE X-RAY SCATTERING}

$\left[\mathrm{C}_{6} \operatorname{mim}\right][\mathrm{Cl}]-\mathrm{H}_{2} \mathrm{O}$ mixtures are hermetically sealed in 2-mm-thick aluminum washer cells with Kapton

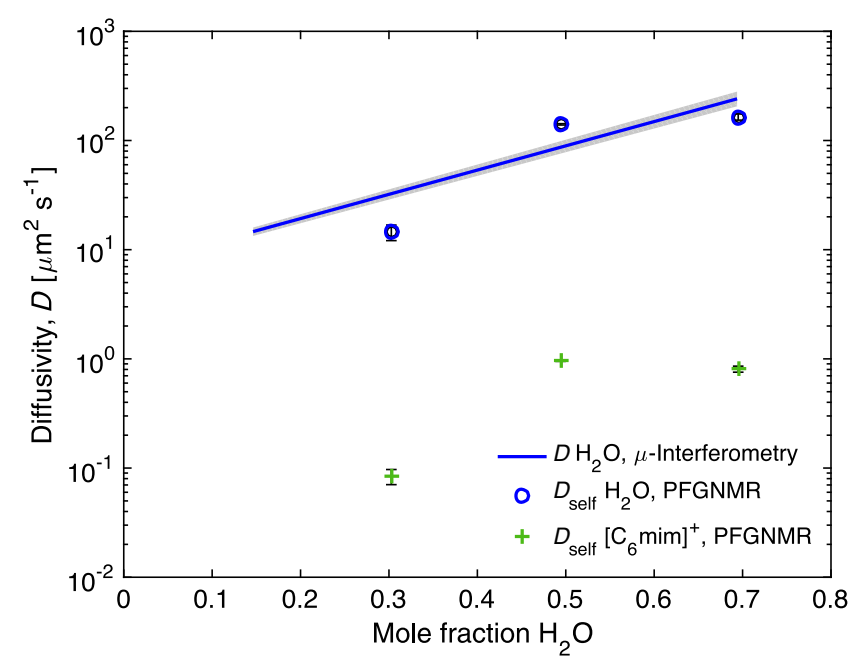

FIG. 12. Diffusivities of species in $\left[\mathrm{C}_{6} \mathrm{mim}\right][\mathrm{Cl}]-\mathrm{H}_{2} \mathrm{O}$ mixtures at ambient temperature. The line indicates continuous diffusivity measured by microfluidic interferometry. Points indicate diffusivities measured by PFGNMR in equilibrium mixtures. Error bars are indicated in black.

windows. Water content is determined using Karl Fischer titration prior to loading. WAXS measurements are performed at beam line 7.3.3 [85] of LBNL's Advanced Light Source over $25^{\circ}-50^{\circ} \mathrm{C}$ at $5^{\circ} \mathrm{C}$ increments. An x-ray beam energy of $10.0 \mathrm{keV}$ is used corresponding to a wavelength $\lambda$ of $1.24 \AA$. Scattering patterns are obtained by first calibrating against silver behenate and then subtracting off the signal from an empty Kapton cell. Azimuthally averaged scattering intensity is plotted versus the magnitude of the momentum transfer vector $q=4 \pi \sin \theta / \lambda$. Scattering data are reduced using the Nika package [86] for Igor Pro.

Figure 13 shows the WAXS spectra for $\left[\mathrm{C}_{6} \mathrm{mim}\right][\mathrm{Cl}]-\mathrm{H}_{2} \mathrm{O}$ mixtures over $25^{\circ}-50^{\circ} \mathrm{C}$ at $5^{\circ} \mathrm{C}$ increments. These spectra are fit to a sum of three Gaussians to determine characteristic domain spacings, which are plotted in Fig. 4(b) for all temperatures. 

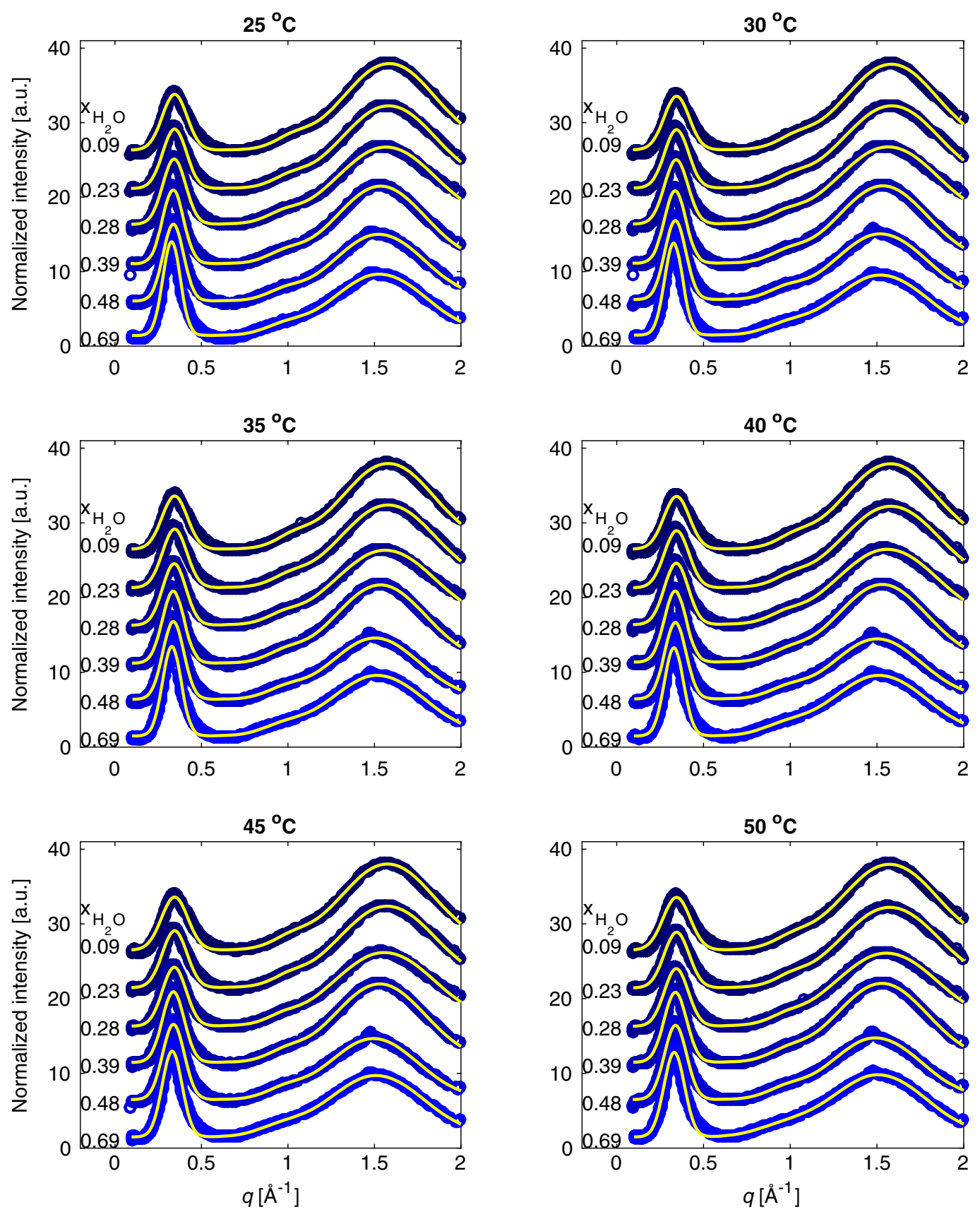

FIG. 13. WAXS spectra (blue points) of $\left[\mathrm{C}_{6} \mathrm{mim}\right][\mathrm{Cl}]-\mathrm{H}_{2} \mathrm{O}$ mixtures over $25^{\circ}-50^{\circ} \mathrm{C}$ in $5^{\circ} \mathrm{C}$ increments. Lines indicate fits to the sum of three Gaussians.

[1] K. R. Seddon, Review Ionic Liquids for Clean Technology, J. Chem. Technol. Biotechnol. 50, 1 (1997).

[2] M. J. Earle and K. R. Seddon, Ionic Liquids. Green Solvents for the Future, Pure Appl. Chem. 72, 1391 (2000).

[3] C. Chiappe and D. Pieraccini, Ionic Liquids: Solvent Properties and Organic Reactivity, J. Phys. Org. Chem. 18, 275 (2005).
[4] M. Galiński, A. Lewandowski, and I. Stepniak, Ionic Liquids as Electrolytes, Electrochim. Acta 51, 5567 (2006).

[5] J. P. Hallett and T. Welton, Room-Temperature Ionic Liquids: Solvents for Synthesis and Catalysis. 2, Chem. Rev. 111, 3508 (2011).

[6] M. Freemantle, Designer Solvents, Chemical and Engineering News 76, 32 (1998). 
[7] F. Kohler, D. Roth, E. Kuhlmann, P. Wasserscheid, and M. Haumann, Continuous Gas-Phase Desulfurisation Using Supported Ionic Liquid Phase (SILP) Materials, Green Chem. 12, 979 (2010).

[8] F. Heym, J. Haber, W. Korth, B. J. M. Etzold, and A. Jess, Vapor Pressure of Water in Mixtures with Hydrophilic Ionic Liquids-A Contribution to the Design of Processes for Drying of Gases by Absorption in Ionic Liquids, Chem. Eng. Technol. 33, 1625 (2010).

[9] F. Karadas, M. Atilhan, and S. Aparicio, Review on the Use of Ionic Liquids (ILs) as Alternative Fluids for $\mathrm{CO} 2$ Capture and Natural Gas Sweetening, Energy Fuels 24, 5817 (2010).

[10] S. Ren, Y. Hou, S. Tian, X. Chen, and W. Wu, What Are Functional Ionic Liquids for the Absorption of Acidic Gases?, J. Phys. Chem. B 117, 2482 (2013).

[11] M. Abai, M. P. Atkins, A. Hassan, J. D. Holbrey, Y. Kuah, P. Nockemann, A. A. Oliferenko, N. V. Plechkova, S. Rafeen, A. A. Rahman, R. Ramli, S. M. Shariff, K. R. Seddon, G. Srinivasan, and Y. Zou, An Ionic Liquid Process for Mercury Removal from Natural Gas, Dalton Trans. 44, 8617 (2015).

[12] S. Tian, Y. Hou, W. Wu, S. Ren, and J. Qian, Hydrophobic Task-Specific Ionic Liquids: Synthesis, Properties and Application for the Capture of SO2, J. Hazard. Mater. 278, 409 (2014).

[13] G. Yu, C. Dai, L. Wu, and Z. Lei, Natural Gas Dehydration with Ionic Liquids, Energy Fuels 31, 1429 (2017).

[14] H. Zhao, S. Xia, and P. Ma, Use of Ionic Liquids as "Green" Solvents for Extractions, J. Chem. Technol. Biotechnol. 80, 1089 (2005).

[15] J. D. Holbrey, I. López-Martin, G. Rothenberg, K. R. Seddon, G. Silvero, and X. Zheng, Desulfurisation of Oils Using Ionic Liquids: Selection of Cationic and Anionic Components to Enhance Extraction Efficiency, Green Chem. 10, 87 (2008).

[16] D. Han and K. H. Row, Recent Applications of Ionic Liquids in Separation Technology, Molecules 15, 2405 (2010).

[17] A. B. Pereiro, J. M. M. Araújo, J. M. S. S. Esperança, I. M. Marrucho, and L. P. N. Rebelo, Ionic Liquids in Separations of Azeotropic Systems-A Review, J. Chem. Thermodyn. 46, 2 (2012).

[18] R. Abro, A. A. Abdeltawab, S. S. Al-Deyab, G. Yu, A. B. Qazi, S. Gao, and X. Chen, A Review of Extractive Desulfurization of Fuel Oils Using Ionic Liquids, RSC Adv. 4, 35302 (2014).

[19] R. I. Canales and J. F. Brennecke, Comparison of Ionic Liquids to Conventional Organic Solvents for Extraction of Aromatics from Aliphatics, J. Chem. Eng. Data 61, 1685 (2016).

[20] E. D. Bates, R. D. Mayton, I. Ntai, and J. H. Davis, CO2 Capture by a Task-Specific Ionic Liquid, J. Am. Chem. Soc. 124, 926 (2002).

[21] M. B. Shiflett, D. W. Drew, R. A. Cantini, and A. Yokozeki, Carbon Dioxide Capture Using Ionic Liquid 1-Butyl-3Methylimidazolium Acetate, Energy Fuels 24, 5781 (2010).

[22] X. Zhang, X. Zhang, H. Dong, Z. Zhao, S. Zhang, and Y. Huang, Carbon Capture with Ionic Liquids: Overview and Progress, Energy Environ. Sci. 5, 6668 (2012).
[23] S. Babamohammadi, A. Shamiri, and M. K. Aroua, A Review of CO2 Capture by Absorption in Ionic LiquidBased Solvents, Rev. Chem. Eng. 31, 383 (2015).

[24] S. Zeng, X. Zhang, L. Bai, X. Zhang, H. Wang, J. Wang, D. Bao, M. Li, X. Liu, and S. Zhang, Ionic-Liquid-Based CO2 Capture Systems: Structure, Interaction and Process, Chem. Rev. 117, 9625 (2017).

[25] A. E. Visser, R. P. Swatloski, W. M. Reichert, J. H. Davis, Jr., R. D. Rogers, R. Mayton, S. Sheff, and A. Wierzbicki, Task-Specific Ionic Liquids for the Extraction of Metal Ions from Aqueous Solutions, Chem. Commun. 0, 135 (2001).

[26] J. A. Whitehead, G. A. Lawrance, and A. McCluskey, "Green" Leaching: Recyclable and Selective Leaching of Gold-Bearing Ore in an Ionic Liquid, Green Chem. 6, 313 (2004).

[27] A. P. Abbott, G. Frisch, J. Hartley, and K. S. Ryder, Processing of Metals and Metal Oxides Using Ionic Liquids, Green Chem. 13, 471 (2011).

[28] Y. Liu, J. Chen, and D. Li, Application and Perspective of Ionic Liquids on Rare Earths Green Separation, Sep. Sci. Technol. 47, 223 (2012).

[29] F. Endres, A. Abbott, and D. R. Macfarlane, Electrodeposition from Ionic Liquids, 2nd ed. (Wiley-VCH, New York, 2017).

[30] M. Vafaeezadeh and H. Alinezhad, Brønsted Acidic Ionic Liquids: Green Catalysts for Essential Organic Reactions, J. Mol. Liq. 218, 95 (2016).

[31] M. McCoy, Chevron Embraces Ionic Liquids, Chemical and Engineering News 94, 16 (2016).

[32] R. L. Vekariya, A Review of Ionic Liquids: Applications towards Catalytic Organic Transformations, J. Mol. Liq. 227, 44 (2017).

[33] G. Cevasco and C. Chiappe, Are Ionic Liquids a Proper Solution to Current Environmental Challenges?, Green Chem. 16, 2375 (2014).

[34] R. D. Rogers and K. R. Seddon, Ionic Liquids-Solvents of the Future?, Science 302, 792 (2003).

[35] L. Chen, M. Sharifzadeh, N. Mac Dowell, T. Welton, N. Shah, and J. P. Hallett, Inexpensive Ionic Liquids: [HSO4]Based Solvent Production at Bulk Scale, Green Chem. 16, 3098 (2014).

[36] A. Kaintz, G. Baker, A. Benesi, and M. Maroncelli, Solute Diffusion in Ionic Liquids, NMR Measurements and Comparisons to Conventional Solvents, J. Phys. Chem. B 117, 11697 (2013).

[37] J. C. Araque, S. K. Yadav, M. Shadeck, M. Maroncelli, and C. J. Margulis, How Is Diffusion of Neutral and Charged Tracers Related to the Structure and Dynamics of a RoomTemperature Ionic Liquid? Large Deviations from StokesEinstein Behavior Explained, J. Phys. Chem. B 119, 7015 (2015).

[38] J. C. Araque, R. P. Daly, and C. J. Margulis, A Link between Structure, Diffusion and Rotations of Hydrogen Bonding Tracers in Ionic Liquids, J. Chem. Phys. 144, 204504 (2016).

[39] A. E. Bradley, C. Hardacre, J. D. Holbrey, S. Johnston, S. E. J. McMath, and M. Nieuwenhuyzent, Small-Angle X-Ray Scattering Studies of Liquid Crystalline 1-Alkyl-3-Methylimidazolium Salts, Chem. Mater. 14, 629 (2002). 
[40] H. Katayanagi, S. Hayashi, H. O. Hamaguchi, and K. Nishikawa, Structure of an Ionic Liquid, 1-n-Butyl-3Methylimidazolium Iodide, Studied by Wide-Angle X-Ray Scattering and Raman Spectroscopy, Chem. Phys. Lett. 392, 460 (2004).

[41] A. Triolo, O. Russina, H.-J. Bleif, and E. Di Cola, Nanoscale Segregation in Room Temperature Ionic Liquids, J. Phys. Chem. B 111, 4641 (2007).

[42] E. Bodo, L. Gontrani, R. Caminiti, N. V. Plechkova, K. R. Seddon, and A. Triolo, Structural Properties of 1-Alkyl-3Methylimidazolium Bis(Trifluoromethyl)Sulfonylamide Ionic Liquids: X-Ray Diffraction Data and Molecular Dynamics Simulations., J. Phys. Chem. B 114, 16398 (2010).

[43] E. Bodo, L. Gontrani, A. Triolo, and R. Caminiti, Structural Determination of Ionic Liquids with Theoretical Methods: C8mimBr and C8mimCl. Strength and Weakness of Current Force Fields, J. Phys. Chem. Lett. 1, 1095 (2010).

[44] B. Aoun, A. Goldbach, S. Kohara, J. F. Wax, M. A. González, and M. L. Saboungi, Structure of a Prototypic Ionic Liquid: Ethyl-Methylimidazolium Bromide, J. Phys. Chem. B 114, 12623 (2010).

[45] B. Aoun, A. Goldbach, M. A. González, S. Kohara, D. L. Price, and M. L. Saboungi, Nanoscale Heterogeneity in Alkyl-Methylimidazolium Bromide Ionic Liquids, J. Chem. Phys. 134, 104509 (2011).

[46] C. Hardacre, J. D. Holbrey, C. L. Mullan, T. G. a. Youngs, and D. T. Bowron, Small Angle Neutron Scattering from 1-Alkyl-3-Methylimidazolium Hexafluorophosphate Ionic Liquids ([Cnmim][PF6], $n=4,6$, and 8), J. Chem. Phys. 133, 074510 (2010).

[47] O. Yamamuro, T. Yamada, M. Kofu, M. Nakakoshi, and M. Nagao, Hierarchical Structure and Dynamics of an Ionic Liquid 1-Octyl-3-Methylimidazolium Chloride, J. Chem. Phys. 135, 054508 (2011).

[48] S. M. Urahata and M. C. C. Ribeiro, Structure of Ionic Liquids of 1-Alkyl-3-Methylimidazolium Cations: A Systematic Computer Simulation Study, J. Chem. Phys. 120, 1855 (2004).

[49] M. Kohagen, M. Brehm, J. Thar, W. Zhao, F. Muller-Plathe, and B. Kirchner, Performance of Quantum Chemically Derived Charges and Persistence of Ion Cages in Ionic Liquids. A Molecular Dynamics Simulations Study of 1-nButyl-3-Methylimidazolium Bromide, J. Phys. Chem. B 115, 693 (2011).

[50] H. Weber, O. Hollóczki, A. S. Pensado, and B. Kirchner, Side Chain Fluorination and Anion Effect on the Structure of 1-Butyl-3-Methylimidazolium Ionic Liquids, J. Chem. Phys. 139, 084502 (2013).

[51] S. Chen, S. Zhang, X. Liu, J. Wang, J. Wang, K. Dong, J. Sun, and B. Xu, Ionic Liquid Clusters: Structure, Formation Mechanism, and Effect on the Behavior of Ionic Liquids, Phys. Chem. Chem. Phys. 16, 5893 (2014).

[52] R. Hayes, G. G. Warr, and R. Atkin, Structure and Nanostructure in Ionic Liquids, Chem. Rev. 115, 6357 (2015).

[53] J. Gao and N. J. Wagner, Water Nanocluster Formation in the Ionic Liquid 1-Butyl-3-Methylimidazolium Tetrafluoroborate ([C4mim][BF4])-D2O Mixtures, Langmuir 32, 5078 (2016).
[54] S. Saha and H.-o. Hamaguchi, Effect of Water on the Molecular Structure and Arrangement of NitrileFunctionalized Ionic Liquids, J. Phys. Chem. B 110, 2777 (2006).

[55] A.-L. Rollet, P. Porion, M. Vaultier, I. Billard, M. Deschamps, C. Bessada, and L. Jouvensal, Anomalous Diffusion of Water in [BMIM][TFSI] Room-Temperature Ionic Liquid, J. Phys. Chem. B 111, 11888 (2007).

[56] A. Menjoge, J. N. Dixon, J. F. Brennecke, E. J. Maginn, and S. Vasenkov, Influence of Water on Diffusion in Imidazolium-Based Ionic Liquids: A Pulsed Field Gradient NMR Study, J. Phys. Chem. B 113, 6353 (2009).

[57] N. Yaghini, L. Nordstierna, and A. Martinelli, Effect of Water on the Transport Properties of Protic and Aprotic Imidazolium Ionic Liquids an Analysis of Self-Diffusivity, Conductivity, and Proton Exchange Mechanism, Phys. Chem. Chem. Phys. 16, 9266 (2014).

[58] T. A. Fadeeva, P. Husson, J. A. Devine, M. F. C. Gomes, G. Steven, and E. W. Castner, Jr., Interactions between Water and 1-Butyl-1-Methylpyrrolidinium Ionic Liquids, J. Chem. Phys. 143, 064503 (2015).

[59] D. R. Vogus, V. Mansard, M. V. Rapp, and T. M. Squires, Measuring Concentration Fields in Microfluidic Channels In Situ with a Fabry-Perot Interferometer, Lab Chip 15, 1689 (2015).

[60] A. Nowbahar, V. Mansard, J. M. Mecca, M. Paul, T. Arrowood, and T. M. Squires, Measuring Interfacial Polymerization Kinetics Using Microfluidic Interferometry, J. Am. Chem. Soc. 140, 3173 (2018).

[61] K. R. Seddon, A. Stark, and M.-J. Torres, Influence of Chloride, Water, and Organic Solvents on the Physical Properties of Ionic Liquids, Pure Appl. Chem. 72, 2275 (2000).

[62] J. G. Huddleston, A. E. Visser, W. M. Reichert, H. D. Willauer, G. A. Broker, and R. D. Rogers, Characterization and Comparison of Hydrophilic and Hydrophobic Room Temperature Ionic Liquids Incorporating the Imidazolium Cation, Green Chem. 3, 156 (2001).

[63] K. Anderson, M. P. Atkins, J. Estager, Y. Kuah, S. Ng, A. A. Oliferenko, N. V. Plechkova, A. V. Puga, K. R. Seddon, and D. F. Wassell, Carbon Dioxide Uptake from Natural Gas by Binary Ionic Liquidwater Mixtures, Green Chem. 17, 4340 (2015).

[64] E. Rilo, M. Domínguez-Pérez, J. Vila, L. Segade, M. García, L. M. Varela, and O. Cabeza, Easy Prediction of the Refractive Index for Binary Mixtures of Ionic Liquids with Water or Ethanol, J. Chem. Thermodyn. 47, 219 (2012).

[65] See Supplemental Material at http://link.aps.org/ supplemental/10.1103/PhysRevX.9.011048 for model-free determination of composition dependent diffusivity.

[66] A. M. Smith, A. A. Lee, and S. Perkin, Switching the Structural Force in Ionic Liquid-Solvent Mixtures by Varying Composition, Phys. Rev. Lett. 118, 096002 (2017).

[67] S. W. Coles, A. M. Smith, M. V. Fedorov, F. Hausen, and S. Perkin, Interfacial Structure and Structural Forces in Mixtures of Ionic Liquid with a Polar Solvent, Faraday Discuss. 206, 427 (2018).

[68] H. V. R. Annapureddy, H. K. Kashyap, P. M. De Biase, and C. J. Margulis, What Is the Origin of the Prepeak in the 
X-Ray Scattering of Imidazolium-Based Room-Temperature Ionic Liquids?, J. Phys. Chem. B 114, 16838 (2010).

[69] O. Borodin, D. L. Price, B. Aoun, M. A. González, J. B. Hooper, M. Kofu, S. Kohara, O. Yamamuro, and M.-L. Saboungi, Effect of Water on the Structure of a Prototype Ionic Liquid, Phys. Chem. Chem. Phys. 18, 23474 (2016).

[70] P. L. Kramer, C. H. Giammanco, and M. D. Fayer, Dynamics of Water, Methanol, and Ethanol in a Room Temperature Ionic Liquid, J. Chem. Phys. 142, 212408 (2015).

[71] C. H. Giammanco, P. L. Kramer, and M. D. Fayer, Ionic Liquid versus $\mathrm{Li}+$ Aqueous Solutions: Water Dynamics near Bistriflimide Anions, J. Phys. Chem. B 120, 9997 (2016).

[72] C. H. Giammanco, P. L. Kramer, D. B. Wong, and M. D. Fayer, Water Dynamics in 1-Alkyl-3-Methylimidazolium Tetrafluoroborate Ionic Liquids, J. Phys. Chem. B 120, 11523 (2016).

[73] S. Cha, M. Ao, W. Sung, B. Moon, B. Ahlström, P. Johansson, Y. Ouchi, and D. Kim, Structures of Ionic Liquidwater Mixtures Investigated by IR and NMR Spectroscopy, Phys. Chem. Chem. Phys. 16, 9591 (2014).

[74] K. Saihara, Y. Yoshimura, and A. Shimizu, Linear Relationship between the 1H-Chemical Shift of Water in a Highly Concentrated Aqueous Solution of an Ionic Liquid and the Jones-Dole B Coefficient, J. Mol. Liq. 212, 1 (2015).

[75] N. Yaghini, J. Pitawala, A. Matic, and A. Martinelli, Effect of Water on the Local Structure and Phase Behavior of Imidazolium-Based Protic Ionic Liquids, J. Phys. Chem. B 119, 1611 (2015).

[76] P. A. Hunt and I. R. Gould, Structural Characterization of the 1-Butyl-3-Methylimidazolium Chloride Ion Pair Using Ab Initio Methods, J. Phys. Chem. A 110, 2269 (2006).

[77] S. Tsuzuki, R. Katoh, and M. Mikami, Analysis of Interactions between 1-Butyl-3-Methylimidazolium Cation and Halide Anions (Cl-, Br-and I-) by Ab Initio Calculations:
Anion Size Effects on Preferential Locations of Anions, Mol. Phys. 106, 1621 (2008).

[78] I. Skarmoutsos, D. Dellis, R. P. Matthews, T. Welton, and P. A. Hunt, Hydrogen Bonding in 1-Butyl-and 1-Ethyl-3Methylimidazolium Chloride Ionic Liquids, J. Phys. Chem. B 116, 4921 (2012).

[79] M. Shukla, N. Srivastava, and S. Saha, Theoretical and Spectroscopic Studies of 1-Butyl-3-Methylimidazolium Iodide Room Temperature Ionic Liquid: Its Differences with Chloride and Bromide Derivatives, J. Mol. Struct. 975, 349 (2010).

[80] H. Mehrer, Diffusion in Solids, Springer Series in Solid-State Sciences Vol. 155 (Springer-Verlag, Berlin, 2007).

[81] V. I. Mel'nikov, The Kramers Problem: Fifty Years of Development, Phys. Rep. 209, 1 (1991).

[82] E. I. Izgorodina, D. Golze, R. Maganti, V. Armel, M. Taige, T. J. S. Schubert, and D. R. MacFarlane, Importance of Dispersion Forces for Prediction of Thermodynamic and Transport Properties of Some Common Ionic Liquids, Phys. Chem. Chem. Phys. 16, 7209 (2014).

[83] E. L. Cussler, Diffusion, 3rd ed. (Cambridge University Press, Cambridge, England, 2009), pp. 71-74.

[84] N. V. Sastry, N. M. Vaghela, and P. M. Macwan, Densities, Excess Molar and Partial Molar Volumes for Water + 1-Butyl-or, 1-Hexyl-or, 1-Octyl-3-Methylimidazolium Halide Room Temperature Ionic Liquids at $T=(298.15$ and 308.15) K, J. Mol. Liq. 180, 12 (2013).

[85] A. Hexemer, W. Bras, J. Glossinger, E. Schaible, E. Gann, R. Kirian, A. MacDowell, M. Church, B. Rude, and H. Padmore, A SAXS/WAXS/GISAXS Beamline with Multilayer Monochromator, J. Phys. Conf. Ser. 247, 012007 (2010).

[86] J. Ilavsky, Nika: Software for Two-Dimensional Data Reduction, J. Appl. Crystallogr. 45, 324 (2012). 